ISSN: $1130-3743$

\title{
VALORES, ACTITUDES Y COMPETENCIAS BÁSICAS DEL ALUMNO EN LA ENSEÑANZA OBLIGATORIA
}

\author{
Student's values, attitudes and basic abilities \\ in compulsory education
}

\author{
Petra María PÉREZ ALONSO-GETA, Paz CÁNOVAS LEONHARDT y \\ Enrique GERVILLA CASTILLO \\ Departamento de Teoría de la Educación. Facultad de Filosofía y Ciencias de la \\ Educación. Universidad de Valencia. Avda. Blasco Ibáñez, 21. 46010 Valencia. \\ Departamento de Teoría e Historia de la Educación. Facultad de Ciencias de la \\ Educación. Universidad de Granada. Campus Universitario de La Cartuja. \\ 18071 Granada.
}

Fecha de aceptación definitiva: marzo de 2000.

BIBLID [(1130-3743) 11, 1999, 53-83]

RESUMEN

En este artículo los autores analizan los valores y competencias de los escolares en nuestro país considerando sus conductas y preferencias aquí y abora, para, sobre esta base también, poder sentar líneas de mejora. Centra su atención en la escuela y, más en concreto, en la Enseñanza Obligatoria, si bien son conscientes de la dificultad de poner límites al campo, por cuanto escuela y sociedad son inseparables en la transmisión de competencias y valores. Es más, la escuela hoy no sería tal si no incorpora los valores de la sociedad para su conocimiento, reflexión y crítica.

La LOGSE, como las grandes leyes educativas precedentes, es hoy para los autores un proyecto político y politizado que pretende la formación de los escolares, en un conjunto de valores y competencias, para el progreso individual y de la sociedad del momento. Tales valores, se concretan, según orden jerárquico, en los siguientes: sociales, dinámicos, intelectuales, globalizadores, individuales, corporales, morales, ecológicos, instrumentales, afectivos y estéticos. Tales valores admiten múltiples vías de realización: contenidos directos de aprendizaje, ejes transversales, medios y métodos, organización, relaciones personales, ambiente escolar, etc. Y aunque todos valen, no todos valen para todos, ni valen lo mismo; sí todos, en mayor o menor grado, humanizan. Entre esta pluralidad de valores y competencias que la LOGSE manifiesta, se ocupan, de la inteligencia, de lo social y del afecto y de la vida saludable. 
The autohors in this paper discuss Spanish school children's values and abilities, considering their behaviours and preferences bere and now, and aiming, also on this ground, at establishing improvement programmes. Although discussion focusses on school and, more specifically, on compulsary education, the authors are aware of how difficult considering school in isolation from society is, as school and society cannot be separated from each other as far as the transfer of abilities and values in concerned. Furhermore, schools could not be considered as such if they did not include the understanding, thinking and criticism of social values.

The authors argue that the LOGSE (Educational System Act), as the main previous Education Acts, is a political and politicized project whose goal is teaching students a set of values and abilities to promote individual and social development. Namely, they are, in a hierachical order, social, dynamic, intelectual, globalizing, individual, physical, moral, ecological, instrumental, emotional and aesthetic values. These values may be transferred in many ways: through direct learning content, cross-curricular learning, resources and methodology, structuring, personal relationships, school atmosphere, etc. Although all of them are worthy, not all of them are adecuate for all the students, neither have the same significance. The all, however, make students human in a higher or lower degree. Within this variety, values and abilities included in the LOGSE are related to intelligence, social aspects, attacbment and bealtby life.

\section{INTRODUCCIÓN}

La expresión educar en valores, frecuente hoy en escritos y discursos, es una redundancia, por cuanto no es posible otro modo de educar más que en valores. El problema, por tanto, no radica en la relación valores-educación (tema indiscutible), sino en qué valores se educa, qué orden jerárquico o preferencial otorgamos a unos sobre otros, dada la pluralidad de valores, sus distintas concepciones, la permanente evolución del sujeto, de la sociedad, de la escuela, etc.

Para no incurrir en la ambigüedad del lenguaje educativo, es preciso clarificar los sentidos o significados de los términos "Valor" $\mathrm{y}$ "Competencia", dadas las múltiples caras o rostros de uno y otro, pues como ya advirtió WITTGENSTEIN, para que haya acuerdo en las opiniones, antes debe de existir acuerdo en el lenguaje. Entre los múltiples sentidos del vocablo competencia dado nuestro contexto educativo, nos inclinamos por el significante sinónimo de capacidad y destreza, de aptitud e idoneidad. Así, el diccionario de la Real Academia de la Lengua, sobre el adjetivo "competente", afirma: "dicese de la persona a quien compete o incumbe alguna cosa, buen conocedor de una técnica, de una disciplina, de un arte.

En este aspecto educativo, referido a la Enseñanza obligatoria, las competencias aluden a valores, a aptitud y destreza en valores, si por valor entendemos una 
PETRA M.. PÉREZ ALONSO-GETA, PAZ CÁNOVAS LEONHARDT Y ENRIQUE GERVILLA CASTILLO

cualidad real o ideal, deseada o deseable por su bondad, cuya fuerza estimativa orienta la vida humana. Con esta definición de valor afirmamos la dimensión ideal y real del valor, así como su vinculación con la naturaleza humana, pues un valor no tiene sentido en la educación si carece de vinculación con el ser humano.

En general no podemos afirmar que todas las competencias hagan referencia a valores; pero sí debemos sostener que todas las competencias deseadas o deseables, referidas al campo de la educación, aluden a valores o valoraciones, pues de lo contrario, serán competencias, pero no educativas.

La LOGSE, en su artículo 13, "obliga" a desarrollar en los niños, al finalizar la Enseñanza Primaria, las siguientes capacidades:

a) Utilizar de manera apropiada la lengua castellana y la lengua oficial propia de la Comunidad Autónoma.

b) Comprender y expresar mensajes sencillos en una lengua extranjera.

c) Aplicar a situaciones de su vida cotidiana operaciones simples de cálculo y procedimientos lógicos elementales.

d) Adquirir las habilidades que permitan desenvolverse con autonomía en el ámbito familiar y doméstico, así como en los grupos sociales con los que se relacionan.

e) Apreciar los valores básicos que rigen la vida y la convivencia humana y obrar de acuerdo con ellos.

f) Utilizar los diferentes medios de representación y expresión artística.

g) Conocer las características fundamentales de su medio físico, social y cultural y las posibilidades de acción en el mismo.

h) Valorar la higiene y la salud de su propio cuerpo, así como la conservación de la naturaleza y el medio ambiente.

i) Utilizar la educación física y el deporte para favorecer el desarrollo personal.

Las competencias/valores a cultivar en la Enseñanza obligatoria son múltiples. De ellos nos iremos ocupando.

\section{VALORES Y COMPETENCIAS BÁSICAS DE LOS ESCOLARES ESPAÑOles (8 A 14 AÑOS)}

En nuestro país, como en el resto de las llamadas sociedades avanzadas, se vive, desde hace años, un cambio gradual de los llamados valores materialistas a los postmaterialistas (Gervilla, E. 1997). De la búsqueda prioritaria de la seguridad económica, física, propio de tiempos de declive económico, hacia posiciones que priman la calidad de vida, necesidades sociales de pertenencia y estima, el medio ambiente o lo estético, más vinculados a períodos prolongados de prosperidad. Este cambio de valores, sin embargo, parece obedecer a un cambio cultural más amplio, que impulsado por el cambio tecnológico, el avance de la denominada "Cultura urbana" y el fenómeno de los mass-media, está transformando las orientaciones, costumbres, normas culturales y formas de organización social de la sociedad occidental. 
Estos cambios socioculturales hacia la postmaterialidad o postmodernidad han modificado profundamente, en los últimos años, las condiciones sociales en las que se lleva a cabo en nuestro país la crianza y educación, a la vez que determinan cambios en los individuos y sus valores, y en la propia cultura infantil.

Los valores tienen un carácter de apreciación subjetivo influidos por el medio cultural y educativo en el que el individuo se socializó y educó. Responden de hecho, desde un punto de vista teórico, a dos hipótesis claves, en primer lugar: la bipótesis de la escasez, según la cual las prioridades de un individuo reflejan su medio socioeconómico, subjetivamente se valora más lo que escasea. En segundo lugar, la hipótesis de la socialización, la relación entre el mundo socioeconómico y los valores personales no tiene un ajuste inmediato, sino que están mediatizados temporalmente, ya que reflejan prioritariamente las condiciones de vida de los individuos de los años previos a la madurez. Es decir, son las condiciones sociales en las que los jóvenes se crían y educan las que configuran prioritariamente su sistema de valores (INGLEHART, R. 1991).

Tradicionalmente, a la escuela se le ha asignado la función de ser transmisora de los conocimientos que los individuos jóvenes necesitaban para la vida futura, a la vez que la socialización y endoculturación en las normas y los valores del grupo. Sin embargo, los contenidos que hoy se aprenden no tienen a la escuela como único referente, aunque todavía hoy educación y escuela sean -para muchos- términos sinónimos. Cuando, desde la perspectiva adulta, se trata de entender a los escolares, no hay que olvidar que estos nacen y crecen en un medio dominado por la sociedad de la información y el consumo.

En una primera aproximación a los valores y competencias de los escolares detallamos distintas proposiciones presentadas a $\operatorname{los}_{\text {niños }}{ }^{1}$, las cuales hacen referencia a valores, modos de ser o conductas según las preferencias que han manifestado, jerarquizadas además de acuerdo a las medias obtenidas. Los resultados determinan el ranking de valores/disvalores y competencias básicas que se refleja en la tabla $\mathrm{n}^{\circ} 1$.

En términos generales puede apreciarse, en primer lugar, cómo los valores ecológicos son muy valorados por los escolares, con un 4'64, 4'54 y 4'51, de media sobre 5, si bien, a la hora de cuidar la Naturaleza "realmente", a su nivel, trayéndose los desperdicios, la media baja considerablemente (4'04), Mas tarde, los valores directamente vinculados a lo que se espera del escolar "modelo", respetuoso, estudioso, se porta bien y que lee para conocer muchas cosas, obediente y con sentido de la amistad y ayuda a los demás. También los valores intelectuales (refle-

1. Estudio para determinar los valores, estilos de vida y bábitos lectores de los escolares españoles en el seguimiento de 8 a 14 años. (S.M.). INCIE. Universidad de Valencia, 1997. La muestra representativa de la población escolarizada española 8 a 14 años quedó configurada por 1.600 individuos lo que garantiza a nivel global un error máximo $+2{ }^{\prime} 5 \%$ con un nivel de confianza del $955^{\prime} 5 \%$. El tipo de muestreo utilizado es el estratificado con afijación proporcional de extracción sucesiva (polietápico). La estratificación se realizó en función del hábitat, sexo, nivel de escolarización, edad y tipo de colegio. 
TABLA N ${ }^{\circ}$ 1. Jerarquía de valores.

\begin{tabular}{|c|c|c|}
\hline \multicolumn{3}{|c|}{ RANKING POR MEDIAS } \\
\hline & ÍTEMS & Porcentaje \\
\hline 1 & El cuidado de la naturaleza nos ayuda a vivir mejor. & 4,64 \\
\hline 2 & Las diferencias de raza, paises, religión no deben separar a las personas & 4,55 \\
\hline 3 & En la naturaleza podemos encontrar cosas bonitas y bellas (paisajes, plantas) & 4,54 \\
\hline 4 & Los ambientes naturales son más sanos y saludables. & 4,51 \\
\hline 5 & Cualquier persona merece respeto. & 4,51 \\
\hline 6 & Estudiar para aprobar. & 4,46 \\
\hline 7 & La amistad y convivencia hace más agradable y alegre la vida. & 4,45 \\
\hline 8 & Es bueno escuchar a los demás. & 4,43 \\
\hline 9 & Portarse bien hace que las personas estén contentas consigo mismo. & 4,38 \\
\hline 10 & Es importante leer para saber, conocer muchas cosas. & 4,38 \\
\hline 11 & Hay que ayudar a conseguir las causas justas. & 4,35 \\
\hline 12 & Escuchar música & 4,28 \\
\hline 13 & Ser obediente tiene sus compensaciones. & 4,22 \\
\hline 14 & $\begin{array}{l}\text { Las personas que intentan pensar las cosas profundamente consiguen más que otras } \\
\text { que actúan sin pararse a pensar. }\end{array}$ & 4,20 \\
\hline 15 & Leer para poder opinar de las cosas. & 4,16 \\
\hline 16 & En una sociedad justa, a la larga las relaciones son mejores entre todos. & 4,12 \\
\hline 17 & Hay que estar dispuesto a trabajar por los demás. & 4,10 \\
\hline & $\begin{array}{l}\text { Sólo se puede hablar de solidaridad si se respetan las diferencias entre los niños (físicas, } \\
\text { costumbres, de raza). }\end{array}$ & 4,07 \\
\hline 19 & $\begin{array}{l}\text { La tolerancia hacía los demás que son diferentes a nosotros (pensar, vestir) cuesta pero } \\
\text { nos hace más felices. }\end{array}$ & 4,05 \\
\hline 20 & $\mathrm{Al}$ ir de excursión suelo traer a casa o echar en alguna papelera los desperdicios. & 4,04 \\
\hline 21 & Dejar, prestar mis cosas. & 4,03 \\
\hline 22 & Ser obediente, aunque sea un rollo. & 4,01 \\
\hline 23 & Ser obediente para que estén contentos conmigo. & 3,98 \\
\hline 24 & Defender a alguien que se le trata injustamente. & 3,94 \\
\hline 25 & La ayuda desinteresada, unida al esfuerzo de cada uno, permite hacer grandes cosas. & 3,92 \\
\hline 26 & Con la familia, amigos, compañeros etc., hoy por ti mañana por mí (dar y recibir). & 3,90 \\
\hline 27 & Suelo dialogar antes que pelear para solucionar problemas. & 3,86 \\
\hline 28 & Dejar mis libros y cuentos aunque me los estropeen. & 3,81 \\
\hline 29 & El tener cosas y poder comprar no hace a las personas más felices. & $\frac{3,0 x}{3,76}$ \\
\hline 30 & Compartir los juguetes y cuentos con otros niños, aunque me los estropeen. & 3,75 \\
\hline 31 & Quien es injusto se busca muchos enemigos. & 3,73 \\
\hline 32 & Sueles tener paciencia, aguantarte de las cosas. & 3,73 \\
\hline 33 & Suelo aguantar al compañero de al lado, aunque no me guste. & 3,71 \\
\hline 34 & Los niños deben hacer lo que ellos estimen v crean correcto. & 3,65 \\
\hline 35 & $\begin{array}{l}\text { Sueles dejar tus apuntes, libretas, etc., a algún compañero o amigo para que vaya bien en } \\
\text { los estudios. }\end{array}$ & 3,52 \\
\hline 36 & El conseguir tener todo lo que quieras a costa de lo que sea no nos hace más felices. & 3,32 \\
\hline 37 & Suelo utilizar la fuerza cuando hace falta & 3,32 \\
\hline 38 & Lo importante es conseguir lo que quieras a costa de lo que sea & 3,13 \\
\hline & $\begin{array}{l}\text { Invitar a una excursión, cumpleaños, jugar, etc., a niños diferentes (en forma de pensar, } \\
\text { gitanos, negros, etc.). }\end{array}$ & 2,97 \\
\hline 40 & Suelo pintar por entretenimiento & 2,96 \\
\hline 41 & Hay que pelear con alguien si hace falta & 2,80 \\
\hline 42 & Suelo pegar cuando se lo merecen & 2,76 \\
\hline 43 & Ir a la mía sin pensar en los demás & 2,62 \\
\hline 44 & La violencia puede ser una vía justa para solucionar algún problema. & 2,33 \\
\hline 45 & Quien pega primero pega mejor. & 2,30 \\
\hline & El dinero es lo más importante del mundo & 2,16 \\
\hline & Escribir cuentos & 1,54 \\
\hline & Visitar museos (pintura, arte) & 0,74 \\
\hline
\end{tabular}


xión, lectura para tener criterio). Siguen en el "ranking” valores prosociales clásicos, de igualdad, respeto, convivencia, justicia, solidaridad, tolerancia, etc. Si bien, se aprecia que se muestran mucho más tolerantes y solidarios con personas de otras razas, países, etc. (4'55) que con el compañero de al lado (3'71) o cuando se trata de invitar a una excursión o cumpleaños a niños diferentes (2'97). Parece que la cercanía hace más difícil la tolerancia con la "diferencia" de los demás. En los últimos puestos del ranking tenemos las conductas más asociales vinculadas a la discriminación, agresividad y violencia. Finalmente, los valores materialistas, «el dinero es lo más importante del mundo", con 2'16 de media y los valores mas vinculados a lo estético (escribir cuentos, visitar museos, etc.). Es curioso que cuando el concepto estético de "lo bello" se asocia a la naturaleza, se sitúa en los primeros puestos del ranking en un 4'55 de media.

Por otra parte, cabe señalar que la posición que ocupa el valor de la sabiduría aparece en las primeras posiciones, con resultados parecidos a los hallados por ROKEACH (1973) con estudiantes del séptimo y octavo grado en Estados Unidos.

En conjunto cabe hablar de que los escolares se sitúan dentro del contexto de los llamados valores postmaterialistas, en los que priman los valores de la naturaleza, la convivencia, las relaciones humanas, frente a los tipificados como materialistas. Los valores estéticos, contrariamente a lo que cabría esperar, salvo, la apreciación de lo "bello", prácticamente no tienen significación. Probablemente, incide también la escasa importancia que se concede a la educación estética en nuestra sociedad.

Después de conocer los valores que los escolares en términos generales más consideran, nos ocuparemos más específicamente de los valores y competencias básicas en la enseñanza obligatoria de 8-16 años, en el campo intelectual, socialafectivo y para una vida saludable.

\subsection{Pensamiento, reflexión y sentido crítico}

Entre todos los aspectos de la razón que deben desarrollarse en la enseñanza obligatoria, es hoy de una especial urgencia y necesidad, dadas las características de nuestra sociedad, la formación del sentido crítico. Actualmente es posible afirmar, y de modo generalizado, que una de las finalidades de la educación, más en concreto de la educación intelectual, es el desarrollo del sentido crítico, esto es, el crecimiento autónomo de la persona para ser cada vez más ella misma. Lograr en el educando una inteligencia crítica es alcanzar un pensamiento propio, que él piense por sí mismo mediante el juicio razonado, lejos de modas, mayorías o temas, a veces, tan actuales como pasajeros.

Ser crítico, pues, no consiste sólo en pensar libremente, ni en censurar toda conducta, ni en mantener una permanente oposición a determinas ideologías, grupos o personas, ni en la variabilidad de quien carece de criterio propio, ni en la espontaneidad, ni menos aún en la defensa de intereses personales o grupales 
PETRA M.․ PÉREZ ALONSO-GETA, PAZ CÁNOVAS LEONHARDT Y ENRIQUE GERVILLA CASTILLO

manifiestos o solapados... sino en la autonomía de criterios fundados acorde con la verdad científica o filosófica. Se trata de una crítica correctamente fundamentada, como expresa la inscripción del frontispicio de la Universidad de Uppsala: «Pensar libremente es algo grande, pero es más grande aún pensar correctamente".

La inteligencia mantiene una profunda relación con la voluntad y con la libertad. La formación del sentido crítico nos conduce a la persona de criterio, esto es, de conducta fundada en reflexiones deliberadas previas, a las decisiones personales. Los diccionarios definen el "criterio" como el principio o la norma de discernimiento y decisión personal acorde con la coberencia y unidad de vida en las más variadas situaciones. No se trata de automatismos o actos reflejos, más propios de los instintos, sino de principios y reglas flexibles y adaptables a las distintas circunstancias.

Ser persona de criterio significa ser capaz de conducir la propia vida de acuerdo con criterios fundados en convicciones racionales y existenciales. En consecuencia, resulta despersonalizador todo cuanto se opone a la actuación de la voluntad libre, bien sea debido a factores externos (ambiente o moda, manipulación, adoctrinamiento), bien a factores internos (caprichos, pasiones). Para prevenir tales prácticas deshumanizadoras, cuya influencia se hace mayor entre los jóvenes, es necesario influir en el dinamismo intelectual y moral para que la persona piense por cuenta propia y piense correctamente, sabiendo discernir lo verdadero de lo falso, A ambas dimensiones ha de contribuir el sentido crítico.

No cabe esperar de los niños, como es lógico, un comportamiento crítico y reflexivo maduro, pero sí han de avanzar en el conocimiento, la reflexión y el sentido crítico, en su desarrollo y logro.

En la tabla $n^{\circ} 2$ podemos apreciar algunas proposiciones que hacen referencia a valores y competencias intelectuales.

Si agrupamos las dos primeras categorías de las distintas proposiciones, obtenemos el siguiente ranking: sabiduria 87 '1\% ("leer para saber, conocer muchas cosas"); reflexión $77^{\prime} 0 \%$ ("las personas que intentan pensar las cosas profundamente consiguen más que aquellos otros que actúan sin pararse a pensar"); leer para tener criterio $76,7 \%$ ("leer para poder opinar de las cosas"); conformación por el grupo 30 '5\%. Se observa que la reflexión y el tener criterio, que hacen referencia al sentido crítico, obtienen prácticamente la misma valoración (77\% y 767\%). El valor sabiduria se sitúa a diez puntos por encima, de éstos, mientras que "ser como el grupo y no pensar por cuenta propia" es valorado por un 30'5\% de los escolares.

Contrariamente a lo que cabría esperar y sería deseable, puede apreciarse cómo a medida que aumenta el nivel de escolarización los alumnos muestran menos interés por saber, pensar y reflexionar. Los datos son estadísticamente significativos. En los ítems en que la variable sexo presenta significación, son las niñas las que muestran mayor inquietud intelectual.

Sin embargo en el ítem "lo importante es ser como los demás" (forma de pensar, intereses, etc.), contrariamente, los valores decrecen a medida que aumenta la escolarización. Sólo el 10’9\% de los alumnos que cursan la ESO están "de acuerdo" frente 
TABLA $\mathrm{N}^{\circ} 2$. Valores y competencias intelectuales.

\begin{tabular}{|c|c|c|c|c|c|c|c|}
\hline Proposición & Mucho & & Bastante & Indiferente & Poco & Nada & $\mathrm{NS} / \mathrm{NC}$ \\
\hline $\begin{array}{l}\text { Qué importancia tiene para ti } \\
\text { "leer para poder opinar de las cosas" }\end{array}$ & $\begin{array}{cccc}43,6 & & \\
\text { niño } & & \text { ni } \\
40,6 & & 4 \\
2^{\circ} \mathrm{C} & 3^{\circ} \mathrm{C} & \mathrm{E} \\
53,1 & 44,2 & 3\end{array}$ & $\begin{array}{l}\text { niña } \\
46,5 \\
\text { ESO } \\
35,6\end{array}$ & 33,1 & 12,3 & 3,3 & 3,1 & 4,6 \\
\hline $\begin{array}{l}\text { Qué importancia tiene para ti } \\
\text { "leer para saber conocer muchas cosas" }\end{array}$ & $\begin{array}{cccc}54,6 & & \\
\text { niño } & & & \text { n } \\
51,8 & & 5 \\
2^{\circ} \mathrm{C} & 3^{\circ} \mathrm{C} & \mathrm{E} \\
66,0 & 59,7 & 4 \\
\end{array}$ & $\begin{array}{l}2 \mathrm{nina} \\
54,7 \\
\mathrm{ESO} \\
40,5\end{array}$ & 31,5 & 6,7 & 2,3 & 2,0 & 2,9 \\
\hline Proposición & Muy de acuer & erdo & $\begin{array}{c}\text { De } \\
\text { acuerdo }\end{array}$ & Indiferente & $\begin{array}{c}\text { En } \\
\text { desacuerdo }\end{array}$ & $\begin{array}{c}\text { Muy en } \\
\text { desacuerdo }\end{array}$ & $\mathrm{NS} / \mathrm{NC}$ \\
\hline $\begin{array}{l}\text { Las personas que intentan pensar las cosas } \\
\text { profundamente consiguen más que aquéllas } \\
\text { otras que actúan sin pararse a pensar }\end{array}$ & $\begin{array}{lll}44,8 & & \\
2^{\circ} \mathrm{C} & 3^{\circ} \mathrm{C} & \mathrm{E} \\
51,9 & 47,4 & 3\end{array}$ & $\begin{array}{l}\text { ESO } \\
36,4\end{array}$ & 32,2 & 113,4 & 2,7 & 2,4 & 4,6 \\
\hline $\begin{array}{l}\text { Lo importante es ser como los demás } \\
\text { (forma de pensar, intereses, etc.) }\end{array}$ & $\begin{array}{lll}16,6 & & \\
2^{\circ} \mathrm{C} & 3^{\circ} \mathrm{C} & \mathrm{E} \\
23,0 & 17,1 & 10\end{array}$ & $\begin{array}{l}\text { ESO } \\
10,9\end{array}$ & 13,9 & 18,8 & 21,9 & 23,8 & 5,0 \\
\hline
\end{tabular}

al 457\%. Probablemente, aquí están incidiendo aspectos relacionados con el narcisismo y la autonomía, de mayor peso a medida que se avanza hacia la adolescencia. Como también la cultura del individualismo, que impera en nuestra sociedad.

\subsection{Competencia emocional y social}

Al inicio de la década de los noventa, SALOVEY, de la Universidad de Yale y MAYER, de New Hampshire, acuñaron por primera vez el término inteligencia emocional para nominar la inteligencia impersonal e intrapersonal. Sin embargo, fue GOLEMAN, psicólogo de Harvard, quien con su libro La inteligencia emocional llamó la atención sobre la importancia del mundo afectivo personal en la vida y el desarrollo de los individuos. La inteligencia emocional comprende capacidades básicas como la percepción y canalización de la propia emoción o la comprensión de los sentimientos de los demás. Tiene su propio dinamismo y actúa constantemente sobre nuestro comportamiento y personalidad. Estas capacidades básicas, que nos permiten tener confianza en nosotros mismos o saber disfrutar de la relación con otras personas, se van formando durante la infancia. Por ello, el profundizar en los rasgos y en la construcción social de las emociones en los escolares, en su competencia emocional, es fundamental en la enseñanza obligatoria.

Las emociones y sentimientos básicos como el hambre, el miedo, la ira, la ansiedad, forman parte del equipamiento emocional, biológicamente están presentes en nuestra naturaleza. Ahora bien, es la cultura la que suministra el vínculo entre lo que los hombres tienen posibilidad de llegar a ser en el campo emocional y lo que realmente llegamos a ser como miembros de ese grupo cultural. En el seno 
de una determinada cultura se aprende a manifestar o controlar sentimientos y emociones de acuerdo a los significados, valores y pautas culturales del grupo. Nuestro equipamiento biológico nos permitirá vivir una serie de vidas afectivas posibles, pero nacemos en una cultura y acabamos viviendo una sola vida cultural. Sin embargo, ser humano es ser algo más que sentir y actuar como miembro de un grupo cultural, hay diferentes modos "individuales" de sentir y ser de ese grupo (edad, status, género, etc.). Este proceso de individualización personal se desarrolla a través de la educación. Gracias a la educación se lleva a cabo la modulación cultural de lo biológico. El ambiente modula la competencia o incompetencia emocional.

\subsubsection{La incompetencia emocional}

Ante la auténtica crueldad de que son autores algunos niños, cabe preguntarse, ¿qué es lo que ba ido mal en el desarrollo de los niños que actúan con violencia? El problema es muy complejo, sobre todo si entendemos que las causas sociales pueden hacer posibles o incluso inevitables los comportamientos humanos, la pérdida de valores, la deprivación social y afectiva en el contexto familiar. La influencia de modelos violentos a través de la TV y otros ámbitos de socialización no hay duda que suponen una carga para el desarrollo del individuo, producen aprendizaje a través del modelado, generan miedo al fracaso y frustración, soledad y baja autoestima, decepción, rabia y agresividad. Componentes básicos, todos ellos, del comportamiento violento.

Pero, esto no significa que los afectados se conviertan, sin más, en agresivos y violentos. Aquellos que han aprendido a manejar la frustración, a tener compasión y, en definitiva, a ser competentes emocionalmente, no utilizarán la violencia para manejarse, ni siquiera cuando experimenten grandes fracasos o agresiones. En nuestra cultura europea está demasiado presente, todavía, la mentalidad del filósofo HOBBES "el hombre es un lobo para el hombre", haciendo referencia al componente innato del comportamiento violento. Sin embargo, la evidencia investigadora muestra, cada vez con más contundencia, que el comportamiento bumano es un reflejo de lo que le acontece y no una consecuencia de sus impulsos innatos. El comportamiento violento y agresivo también se aprende. Los factores genéticos o innatos que configuran comportamientos humanos como la compasión, el altruismo o la agresión son el producto de un largo proceso condicionado por las experiencias familiares y escolares, las normas sociales y los patrones culturales. Se aprende a ser agresivo de la misma forma que a inhibir la agresión y ser compasivo. Ambos son biológicamente posibles.

Cuando la conducta agresiva es ridiculizada y reprimida en un grupo humano, acaba por desaparecer, de igual forma que cuando constituye una forma eficaz de manejar la situación se potencia y es cada vez más frecuente. El ser humano, contando con unas potencialidades de ser agresivo, amar o hablar, se desarrolla en 
contacto con el grupo social en que vive y, en virtud de los modelos y las condiciones de vida a que se ve expuesto, organiza su conducta.

Los padres, cuidadores y profesores en los entornos donde no se fomenta la competencia emocional, según la evidencia empírica, suelen tener creencias sesgadas negativas, acerca de las características de sus niños, tienden a verlos menos inteligentes, más problemáticos, agresivos y desobedientes. Comprenden mal las necesidades afectivas y motivaciones de los niños, reconocen mal sus expresiones emocionales; responsabilizan más a los niños por su conducta negativa y les atribuyen frecuentemente intenciones de comportarse negativamente. Tienen una mala comunicación y escasa cohesión grupal. Asimismo, despliegan una menor empatía, no se ponen en el lugar de los niños, manifiestan poca compasión y, en términos generales, les conmueve poco el llanto infantil. Estos comportamientos familiares tienen consecuencias profundas en los niños (PÉREZ ALONSO-GETA, P.; y CÁNOVAS LEONHARDT, P., 1996).

\subsubsection{Claves de la competencia emocional}

La emoción del satri emotio se define en el diccionario de la Real Academia de la Lengua como "estado de ánimo producido por impresiones de los sentidos, ideas o recuerdos que con frecuencia se traduce en gestos, actitudes u otras formas de expresión". Para GOLEMAN (1996), el término emoción se refiere a un sentimiento y a los pensamientos, los estados biológicos, psicológicos y el tipo de tendencias a la acción que lo caracterizan. Existen numerosas emociones, a la vez que múltiples matices y variaciones entre ellas. P. EKMAN, de la Universidad de California, tras un estudio transcultural describe las emociones en términos de grandes familias o dimensiones básicas reconocidas por todas las culturas y representativas de los infinitos matices de la vida emocional (ira, miedo, afecto, etc.).

\subsubsection{La imaginación emocional}

La capacidad imaginativa en la infancia desempeña un papel fundamental en el desarrollo de la compresión de la realidad social en general y de la construcción social de las emociones en particular. Sirve a la comprensión de la complejidad de los sentimientos, la comprensión del engaño o la importancia de las reglas culturales en la manifestación y control de la expresión emocional en un contexto social. La forma en como evoluciona y se desarrolla la imaginación en la vida infantil está influenciada por los acontecimientos sociales, las fuerzas culturales, el contexto concreto en el que vive el niño o niña y los presupuestos desde los que son tratados en casa y en el centro escolar. Tiene que ver con las respuestas a las experiencias afectivas que van teniendo día a día en la familia y la clase.

La imaginación emocional se sitúa en ese lugar propio de pensamientos y ensoñaciones donde es posible el reconocimiento de las emociones, sentimientos 
PETRA M..$^{a}$ PÉREZ ALONSO-GETA, PAZ CÁNOVAS LEONHARDT Y ENRIQUE GERVILLA CASTILLO

VALORES, ACTITUDES Y COMPETENCIAS BÁSICAS DEL ALUMNO EN LA ENSEÑANZA OBLIGATORIA

y motivos propios y ajenos. Su desarrollo permite manejarse y controlar afectivamente la situación. La imaginación emocional permite adoptar la perspectiva del otro, empezar a comprender sus sentimientos y emociones, así como los motivos y razones de su conducta. Permite también anticipar los propios patrones de acción imaginando los patrones de percepción emocionales. La imaginación y la capacidad de simular permiten también al niño concebir las posibles realidades que otras personas sienten.

\subsubsection{Los pilares de la inteligencia emocional}

La competencia emocional puede entenderse como la capacidad que permite a la especie humana solucionar el problema de la vida. La inteligencia emocional podría explicarse desde cuatro pilares o parámetros básicos: la capacidad de entender y comprender emociones y sentimientos propios, la autoestima, la capacidad de gestionar y controlar los impulsos y situaciones afectivas y la capacidad de entender y comprender los sentimientos de los demás.

Tener competencia emocional es algo que requiere entrenamiento y aprendizaje y, como tal, puede enseñarse. Llegar a ser competentes emocionalmente requiere una educación que empieza en los primeros años de la vida. Requiere que quienes cuidan de los niños les ayuden a desarrollar las cualidades o pilares básicos de la competencia emocional.

\section{Capacidad de entender y comprender las propias emociones}

El reconocimiento de las propias emociones es el alfa y el omega de la competencia emocional. Sólo cuando se aprende a percibir las señales emocionales, a categorizarlas y aceptarlas, es posible dirigirlas y canalizarlas adecuadamente sin dejarse arrastrar por ellas. Para GOLEMAN (1996, p. 85), el conocimiento de uno mismo y de los propios sentimientos es la piedra angular de la inteligencia emocional, la base que permite progresar. La toma de conciencia emocional constituye la habilidad emocional fundamental, el cimiento sobre el que se asientan otras habilidades y pilares emocionales. La comprensión, que acompaña a la conciencia de uno mismo, tiene un poderoso efecto sobre los sentimientos negativos intensos y nos proporciona la oportunidad de liberarnos de ellos. Consecuentemente, se tiende a tener una visión positiva de la vida y a percibirse como una persona controlada y autónoma. Por el contrario, las personas atrapadas por sus emociones se ven desbordadas e incapaces de escapar de ellas.

Como es lógico, no es posible para los niños/as disponer, de entrada, ni en mucho tiempo, de tal repertorio de habilidades, pero se pueden ir sentando las bases para su adquisición. La adquisición de la conciencia de "sí-mismo" se desarrolla continuamente a lo largo de la infancia en relación con otros procesos cognitivos y de socialización, los cuales van a permitir, finalmente, la representación e identificación del "yo" y de los propios sentimientos y emociones. 
PETRA M. a PÉREZ ALONSO-GETA, PAZ CÁNOVAS LEONHARDT Y ENRIQUE GERVILLLA CASTILLO VALORES, ACTITUDES Y COMPETENCIAS BÁSICAS DEL ALUMNO EN LA ENSEÑANZA OBLIGATORIA

\section{La autoestima}

Otro de los pilares básicos de la inteligencia emocional es, sin duda, la autoestima, directamente vinculada al autoconcepto y a la comprensión y sentimientos propios. Sin entrar aquí en cuestiones terminológicas, el autoconcepto puede entenderse como el esquema mental que permite definirnos. Es la visión e imagen que el individuo tiene de sí mismo, incluye en la conducta y es el mediador entre la persona y el medio. El conocimiento de sí mismo y la consiguiente autoimagen, el autoconcepto, es una estructura central para entender la concepción del mundo del sujeto y una de las principales variables que influyen en las acciones de éste. Interactuando con factores biológicos y fuerzas situacionales externas, dirige y guía su conducta. De todos los juicios a los que el individuo se somete ninguno es tan fundamental como la evaluación de sí-mismo. Del resultado de esta evaluación resulta la autoestima. Este concepto modula el presente y futuro del individuo y es el factor principal de su vida personal y social. En la autoestima se combinan dos proceso mutuamente relacionados: la propia evaluación y la subsiguiente respuesta afectiva (positiva o negativa) al contenido de la misma.

Entre los factores más influyentes en la formación de la autoestima podemos señalar: El éxito o fracaso en dominios altamente valorados en el individuo (en relación directa al sistema de creencias personales). La valoración recibida de los demás, con especial incidencia de los "otros", el profesor se presenta aquí como facilitador de experiencias positivas o negativas en el aula (proceso de enseñanzaaprendizaje y en las relaciones entre iguales). Comparación social, la comparación con los otros se suele utilizar como base para inferir juicios acerca de la propia competencia en distintas áreas. Esto aumenta a partir de los 10-12 años (GONZÁLEZ Y TOURÓN, p. 150). Finalmente, las atribuciones, que hacen referencia a los juicios sobre las causas de los resultados de éxito o fracaso en diferentes dominios conductuales. Para contribuir al desarrollo de la autoestima será preciso plantear a los niños metas alcanzables con su esfuerzo, donde puedan desarrollar y poner en acción los propios recursos e intentar, en lo posible, que puedan percibir el fruto de su implicación y esfuerzo.

La capacidad de gestionar y controlar inteligentemente los impulsos $y$ situaciones afectivas

Las emociones básicas del ser humano forman parte de su naturaleza biológica, lo quiera o no, pero la posibilidad de manejar estas formas de comportamiento en un sentido u otro, dentro de un contexto cultural, está en sus manos. Aquí tiene una importancia capital la educación. El autocontrol puede entenderse como la capacidad de dirigir de forma autónoma la propia conducta. La autorregulación es un aspecto esencial del desarrollo humano que permite al hombre controlar la situación y no estar a merced de las demandas del entorno. Nos enseña a "esperar" cuando las cosas no pueden obtenerse inmediatamente, a "Variar" las estrategias cuando éstas no funcionan y a "evitar" comportamientos inadecuados. Emociones básicas de nuestro 
bagaje emocional, como el miedo, la ira, etc. son además mecanismos de supervivencia que no se pueden desconectar o evitar, pero se pueden conducir y canalizar de forma fructífera. El componente biológico primario emocional, como puede ser el deseo o la lucha, puede ser sustituido por formas de comportamiento aprendidas y culturalmente aceptadas, como el flirteo o la ironía. Controlar el impulso, superar la frustración, es fundamental en la competencia emocional.

\section{La capacidad de comprender y entender los sentimientos de los demás}

R. ROSENTHAL, hace ya bastantes años, mostró que la inteligencia emocional está vinculada a la capacidad de leer los sentimientos de los demás. La importancia de la percepción del otro o empatía para la competencia emocional es indudable, pues ésta se desarrolla por la comunicación emocional en situaciones de interacción. La disposición natural a la empatía la manifiestan los niños muy pronto. Bebés de tres meses reaccionan alterándose ante el llanto de otro niño y comienzan ellos mismos a llorar. Parece que se trata de una capacidad innata que, sin embargo, es necesario cultivar. Para el psiquiatra STERN, el desarrollo de la empatía depende de la sensibilidad y reacciones de los padres frente a las manifestaciones emocionales del niño, tanto si se ignoran como si se sobrepasan.

La compasión es un elemento de competencia emocional y resulta serlo también de la competencia social e incluso moral. En este último sentido, el modelo de perfección para el más alto desarrollo humano parte del budismo, es alguien "que ha puesto fin a su sufrimiento y a crear sufrimiento a los demás". De ahí, que la compasión se encuentre en los cimientos mismos del sistema ético (YEARLEY, p. 26).

En torno a la competencia emocional y social la investigación empírica ha puesto de manifiesto algunos datos que, si bien brevemente-dado el contexto de este trabajo-, queremos reseñar. El grado de competencia emocional de los niños se pone de manifiesto en situaciones y contextos naturales a través de lo que los niños piensan y hacen. En la tabla $n^{\circ} 3$ podemos apreciar distintas proposiciones en referencia a los mismos.

En primer lugar, podemos observar que un gran porcentaje de niños/as (36'8\% "Siempre" y 28'4\% "muchas veces") apuestan por el diálogo, la consideración del punto de vista del otro, antes que por la pelea. Indica una buena predisposición a tener en cuenta el otro, aceptarlo frente a la ruptura que provoca la agresión.

En términos generales, puede decirse que los escolares de 8 a 14 años se encuentran más cercanos a la competencia que a la incompetencia socioemocional, con posturas que apuestan mayoritariamente por el diálogo para solucionar los problemas ( $65^{\prime} 2 \%$, "siempre" y "muchas veces"). Tienen paciencia con los compañeros (58'4\%, "siempre" y "muchas veces"), lo que implica cierto control emocional. Se conmueven cuando transgreden la norma ( $74 \%$ ' "siempre" y "muchas veces"), y son capaces de mostrar empatía jugando y ayudando a los que no tienen amigos (57'1\%, "siempre" y "muchas veces"). No obstante, aparece siempre un porcentaje pequeño de niños que muestran incompetencia emocional y una conducta claramente antisocial. 


\section{TABLA $\mathrm{N}^{\circ}$ 3. Nos gustaria saber con qué frecuencia llevas a cabo las siguientes conductas y actividades.}

\begin{tabular}{|c|c|c|c|c|c|c|c|}
\hline Proposición & Siempre & $\begin{array}{l}\text { Muchas } \\
\text { veces }\end{array}$ & $\begin{array}{l}\text { Algunas } \\
\text { veces }\end{array}$ & $\begin{array}{l}\text { Muy } \\
\text { pocas } \\
\text { veces }\end{array}$ & Nunca & NS/NC & $\mathrm{X}$ \\
\hline $\begin{array}{l}\text { Suelo dialogar antes que pelear } \\
\text { para solucionar un problema }\end{array}$ & $\begin{array}{|lll|}36,8 & & \\
2^{\circ} \mathrm{C} & 3^{\circ} \mathrm{C} & \text { ESO } \\
41,3 & 36,2 & \\
\end{array}$ & $\begin{array}{l}28,4 \\
33,4 \\
\end{array}$ & 18,9 & 7,3 & 5,7 & 3,0 & 3,86 \\
\hline $\begin{array}{l}\text { Aguantar al compañero de al lado, } \\
\text { aunque no me guste }\end{array}$ & $\begin{array}{lll}32,7 & & \\
2^{\circ} \mathrm{C} & 3^{\circ} \mathrm{C} & \mathrm{ESO} \\
39,6 & 35,1 & 24,7 \\
\end{array}$ & 26,2 & 19,7 & 9,4 & 7,1 & 4,9 & 3,71 \\
\hline $\begin{array}{l}\text { Suelo portarme bien porque así } \\
\text { estoy a gusto conmigo mismo }\end{array}$ & $\begin{array}{|ccc|}39,4 & & \\
\text { niños } & & \text { niñas } \\
36,8 & & 42,0 \\
2^{\circ} \mathrm{C} & 3^{\circ} \mathrm{C} & \mathrm{ESO} \\
50,2 & 41,1 & 29,0 \\
\end{array}$ & 32,5 & 17,9 & 3,9 & 2,3 & 3,8 & 4,07 \\
\hline $\begin{array}{l}\text { Sueles tener paciencia, aguantarte } \\
\text { con los que tardan más en hacer las cosas } \\
\text { (correr, tareas, dibujar). } \\
\text { Aunque perjudique al grupo }\end{array}$ & $\begin{array}{|lll|}28,1 & & \\
2^{\circ} \mathrm{C} & 3^{\circ} \mathrm{C} & \mathrm{ESO} \\
34,6 & 25,8 & 24,8 \\
\end{array}$ & 30,3 & 27,6 & 6,1 & 4,9 & 2,9 & 3,73 \\
\hline $\begin{array}{l}\text { Cuando has hecho algo malo, } \\
\text { te sientes mal aunque no te pillen }\end{array}$ & $\begin{array}{|lll|}49,9 & & \\
2^{\circ} \mathrm{C} & 3^{\circ} \mathrm{C} & \text { ESO } \\
56,2 & 53,5 & 41,2 \\
\end{array}$ & 24,9 & 13,0 & 5,3 & 2,8 & 4,1 & 4,19 \\
\hline Ayudas y juegas con los que no tienen amigos & $\begin{array}{|lll|}30,4 & & \\
2^{\circ} \mathrm{C} & 3^{\circ} \mathrm{C} & \text { ESO } \\
42,7 & 30,7 & 20 \\
\end{array}$ & 26,7 & 27,8 & 8,1 & 3,5 & 3,4 & 3,75 \\
\hline $\begin{array}{l}\text { Obedeces y mantienes buenas relaciones con } \\
\text { los otros para que te consideren "legal", bueno }\end{array}$ & $\begin{array}{|lll|}35,3 & & \\
2^{\circ} \mathrm{C} & 3^{\circ} \mathrm{C} & \text { ESO } \\
39,6 & 36,1 & 30,9 \\
\end{array}$ & 33,6 & 19,4 & 4,4 & 3,1 & 4,2 & 3,98 \\
\hline
\end{tabular}

En este sentido, si agrupamos las dos últimas categorías de la escala, "muy pocas veces" $\mathrm{y}$ "nunca", que representan la incompetencia socioemocional, obtenemos el siguiente ranking de proposiciones: “Aguantar al compañero de al lado, aunque no me guste", 16 '5\%; "Suelo dialogar antes que pelear para solucionar problemas", 13'0\%; "Ayudas y juegas con los que no tienen amigos", 11'6\%; "Sueles tener paciencia, aguantarte, con los que tardan más en hacer las cosas (correr, tareas, dibujar), aunque perjudique al grupo", 11\%; "Cuando has hecho algo mal, te sientes mal aunque no te pillen", $81 \%$; "obedeces y mantienes buenas relaciones para que te consideren legal, bueno", 7'5\% y, finalmente, "Suelo portarme bien, porque así estoy a gusto conmigo mismo", 6'2\%. Puede apreciarse siempre por encima del $10 \%$ un primer bloque que, en sentido negativo, encabezan los niños, para los cuales se hace difícil aguantar al compañero de al lado (no son tolerantes), no suelen dialogar para solucionar los problemas, no ayudan y juegan con los que no tienen amigos (excluyen, no son solidarios), no tienen paciencia, (no se ponen en el lugar del otro). El segundo bloque se relaciona más con propuestas personales, y los porcentajes bajan significativamente. Un 8'1\% no se siente mal cuando han hecho algo mal. En menor proporción no suelen obedecer ni les interesa portarse bien para que les consideren bien, ni para estar a gusto con ellos mismos. Los datos parecen poner de manifiesto que 
a un grupo de niños, más o menos cercano al 15\%, les resulta difícil asumir el valor de la tolerancia y, con ello, la solidaridad y el respeto a la diferencia con los más cercanos, en situaciones inmediatas (clase, juegos, etc.).

Cuando los datos se cruzan con las variable sexo y nivel de escolarización, y muestran diferencias estadísticamente significativas, son las niñas frente a los niños/as que presentan mayor competencia emocional. En cuanto al nivel de escolarización, los datos aparecen de manera significativa configurando mayor incompetencia emocional a medida que aumenta la edad, especialmente los escolares que cursan la E.S.O.

Las tendencias son preocupantes si entendemos que las competencias y valores aprendidos durante la infancia, con los refuerzos convenientes, permanecen durante toda la vida sirviendo como "modelo" y sistema organizado en la orientación y la motivación de la acción a nivel general. Estos sistemas de valores culturales se mantiene sólo si se ajustan a la estimación individual, si se aprecian, y gradualmente cada vez más, se valoran y viven personalmente, lo que en este caso no parece estar asegurado.

En tabla $\mathrm{n}^{\circ} 4$ podemos observar cómo son nuevamente las niñas frente a los niños las que presentan una mayor competencia socio-emocional y cómo los escolarizados en la ESO se muestran más de acuerdo con el uso de conductas violentas.

Sólo el 45'5\% está "muy de acuerdo" en "hablar antes que pelear para solucionar los problemas".

Un niño que vive en un entorno agresivo, donde el lenguaje y el diálogo están presentes como vía de resolución de los problemas, donde la convivencia con los demás se hace posible a través del entendimiento y la armonía, aprenderá a expresarse a través del lenguaje y de la razón. Contrariamente, si experimenta el rechazo, la frustración o la agresión provocada por un entorno hostil, donde la falta de

\section{TABLA $\mathrm{n}^{\circ}$ 4. Nos gustaría que nos dijeras qué piensas de algunas afirmaciones $y$ situaciones.}

\begin{tabular}{|c|c|c|c|c|c|c|c|}
\hline Proposición & $\begin{array}{l}\text { Muy de } \\
\text { acuerdo }\end{array}$ & $\begin{array}{c}\text { De } \\
\text { acuerdo }\end{array}$ & Indiferente & $\begin{array}{c}\text { En } \\
\text { desacuerdo }\end{array}$ & $\begin{array}{l}\text { Muy en } \\
\text { desacuerdo }\end{array}$ & $\mathrm{NS} / \mathrm{NC}$ & $\mathrm{X}$ \\
\hline Hay que pelear con alguien si hace falta & $\begin{array}{|ll|}15,0 & \\
\text { niño } & \text { niñ } \\
19,7 & 10 \\
\end{array}$ & 16,8 & 20,8 & 20,0 & 23,1 & 4,3 & 2,8 \\
\hline $\begin{array}{l}\text { La violencia puede ser una vía justa } \\
\text { para solucionar algunos problemas }\end{array}$ & $\begin{array}{cc}9,5 & \\
\text { niño } & \text { niñ } \\
12,6 & 6, \\
\end{array}$ & 12,7 & 15,5 & 20,8 & 37,4 & 4,1 & $\begin{array}{c}2,3 \\
3\end{array}$ \\
\hline $\begin{array}{l}\text { Hay que hablar antes de pelear } \\
\text { para solucionar los problemas }\end{array}$ & $\begin{array}{lll}56,8 & & \\
\text { niño } & & \text { niñ } \\
51,6 & & 62 \\
2^{\circ} \mathrm{C} & 3^{\circ} \mathrm{C} & \mathrm{ES} \\
641 & 62,5 & 45\end{array}$ & 26,9 & 6,3 & 2,8 & 2,2 & 5,1 & $\begin{array}{c}4,4 \\
0\end{array}$ \\
\hline Quien pega primero pega mejor & $\begin{array}{cc}10,1 & \\
\text { niño } & \text { niñ } \\
12,9 & 7,\end{array}$ & 8,6 & 17,6 & 23,1 & 36,3 & 4,3 & $\begin{array}{c}2,3 \\
0\end{array}$ \\
\hline
\end{tabular}




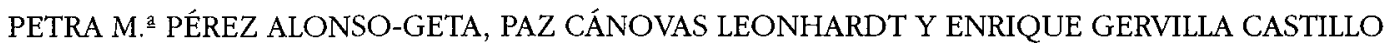
VALORES, ACTITUDES Y COMPETENCIAS BÁSICAS DEL ALUMNO EN LA ENSEÑANZA OBLIGATORIA

entendimiento, la violencia y la ausencia de diálogo son pautas normales de conducta, aprenderá que mediante comportamientos agresivos puede conseguir sus propósitos con más facilidad. De ahí, la importancia de generar un entorno de competencia emocional y no violencia en la escuela. Sobre todo, si atendemos a ese 22 ' $2 \%$ que se muestran ("muy de acuerdo" y "de acuerdo") en que "hay que pelear con alguien si hace falta"; o ese 18,7\% ("muy de acuerdo" $\mathrm{y}$ "de acuerdo") en que "quien pega primero pega mejor".

En referencia al autoconcepto, los niños, como cualquier ser humano, buscan optimizar su valoración a través de los demás (referentes significativos) y de sí mismos. En la tabla $n^{\circ} 3$ podemos observar cómo las niñas presentan una referencia más centrada en sí mismas, "suelo portarme bien porque así estoy a gusto conmigo mismo", el 42'0\% frente al 36'8\%. Los datos son estadísticamente significativos.

Centrándonos en la variable edad, con datos también significativos, vemos que, contrariamente a lo deseable, a medida que sube el nivel de escolarización los porcentajes bajan significativamente: $50 \prime 2 \%, 2^{\circ}$ ciclo; 41 ' $1 \%, 3^{\circ}$ ciclo; $29 \% 0 \%$, ESO.

La misma tendencia, con valores significativos, se observa en el ítem "Obedeces y mantienes buenas relaciones con los otros, para que te consideren "legal", bueno": 39' $6 \%$, $2^{\circ}$ ciclo; 36'1\%, $3^{\circ}$ ciclo; 30'9\%, ESO. En este caso, sin embargo, la variable sexo no presenta significación estadística.

Los datos apuntan a que "el portarse bien" no es un dominio "altamente valorado" por los escolares más mayores y, por tanto, no será un factor influyente para la formación del autoconcepto en esta edad y nivel de escolarización de la ESO. En sentido contrario para las niñas "portarse bien para sentirse bien consigo mismo" sí que es un referente importante en la fundamentación de su autoestima.

Los datos coinciden con los resultados obtenidos sobre el autoconcepto (PÉREZ ALONSO-GETA, Ma ., CÁNOVAS LEONHARDT, 1995) en la etapa de la preadolescencia y adolescencia en los que aparecen individuos con un elevado autoconcepto y sentimientos de autovalía, aunque no sean competentes en "dominios" valorados como relevantes por los adultos o la mayoría de la sociedad (como "portarse bien" o que "te consideren legal, bueno"). Pero sí son importantes y claves dentro del grupo social de iguales. Estos individuos pueden aparecer como problemáticos para los adultos, y sin embargo su autoconcepto suele ser positivo. Aquí entramos en el sistema de valores y creencias personales en el cual la referencia de la "acción valorada" en el grupo de iguales es concluyente.

Por otra parte, si comparamos las proposiciones "Hay que hablar antes que pelear para solucionar los problemas" (tabla $\mathrm{n}^{\circ} 4$ ) y "Suelo dialogar antes que pelear para solucionar un problema" (tabla $\mathrm{n}^{\circ} 3$ ) que hacen referencia a "valor" $\mathrm{y}$ "competencia", respectivamente, en el mismo ámbito, se observa cómo los escolares, en términos generales, se decantan por el diálogo en mayor porcentaje (56'8\%), a nivel teórico y lejano mientras que baja el porcentaje $(36,8 \%)$ cuando se trata de poner en marcha la misma conducta. Puede observarse, asimismo, que se da una mayor coherencia entre pensamiento y acción a medida que sube el nivel de escolarización (en la E.S.O. $45,5 \%$ y $33,4 \%$, respectivamente), aunque las diferencias entre lo que piensan que es bueno hacer y lo que realmente hacen, sigan siendo importantes. 
PETRA M. a PÉREZ ALONSO-GETA, PAZ CÁNOVAS LEONHARDT Y ENRIQUE GERVILLA CASTILLO

\subsubsection{El desarrollo de la competencia social en la educación obligatoria}

En un sentido amplio, el término competencia social se refiere a una adaptación social saludable. Ciertamente, es un elemento clave del desarrollo humano que incluye la capacidad de autocontrol, a la vez que conlleva un juicio valorativo (personal y social) de la adecuación de dicha conducta, siempre en referencia al contexto socio-cultural es que éste se desarrolla. Así, la consideración de una conducta como competente socialmente depende de situaciones tanto sociales como evolutivas.

Dentro de la educación obligatoria, la noción de competencia social enfatiza sobre todo la capacidad de adaptación a los diferentes contextos, así como la posibilidad de establecer relaciones recíprocas satisfactorias con iguales. No podemos olvidar que la vida social en la escuela adquiere una significación muy especial para el niño/a. Se produce la unión de sus dos mundos vitales, en los que ha de ser hábil socialmente: familia y escuela.

La competencia social, desde nuestra perspectiva, se fundamenta en dos aspectos relevantes: un aspecto interno, que hace referencia a procesos cognitivos y socioemocionales, donde se incluye la adopción de perspectiva social, la empatía y la capacidad de autorregulación. Y un aspecto externo, directamente vinculado a las habilidades sociales, que supone la valoración y apoyo por parte de los adultos, y la aceptación o, en su defecto, el rechazo por parte del grupo de iguales. De ahí, que competencia emocional y social aparezcan íntimamente relacionadas.

En primer lugar, es a través de la cooperación en el juego y, más tarde, en la escuela donde se establecen las relaciones interpersonales. A partir de aquí, existe la posibilidad de sentirse integrado, de expresar opiniones e ir confrontando puntos de vista. Necesidades básicas para el individuo que la educación en esta etapa debe cubrir.

En los comienzos de la educación primaria, el niño/a ya es capaz de desarrollar estrategias de comprensión y asimilación del mundo social que le permiten abordar situaciones desde diferentes puntos de vista, por ejemplo, considerando la perspectiva de un compañero de clase. Al respecto, cabe señalar que existe un paralelismo entre evolución intelectual y desarrollo social. El niño es capaz de cooperar con los otros cuando se halla capacitado para comprender la reciprocidad y complementariedad de otros puntos de vista.

No obstante, aunque en realidad existe este paralelismo, en ocasiones nos encontramos con niños en esta etapa capaces de resolver problemas, por ejemplo de matemáticas, considerando distintas perspectivas, pero quizá en una situación conflictiva les resulta difícil tener en cuenta el punto de vista de un compañero para solucionar dicho conflicto (tabla $\mathrm{n}^{\circ}$ ).

Nos parece preocupante que a medida que aumenta el nivel educativo disminuya la frecuencia de utilización del diálogo $\left(41,3 \%, 362 \%, 33^{\prime} 4 \%\right.$, respectivamente) frente a otra alternativa como puede ser el empleo de la fuerza. 
PETRA M. P PÉREZ ALONSO-GETA, PAZ CÁNOVAS LEONHARDT Y ENRIQUE GERVILLA CASTILLO VALORES, ACTITUDES Y COMPETENCIAS BÁSICAS DEL ALUMNO EN LA ENSEÑANZA OBLIGATORIA

TABLA $N^{\circ}$ 5. Frecuencia de utilización del diálogo frente a otra alternativa según nivel educativo.

\begin{tabular}{|l|c|c|c|c|c|c|}
\hline & Siempre & $\begin{array}{c}\text { Muchas } \\
\text { veces }\end{array}$ & $\begin{array}{c}\text { Algunas } \\
\text { veces }\end{array}$ & $\begin{array}{c}\text { Muy pocas } \\
\text { veces }\end{array}$ & Nunca & NS/NC \\
\hline $2^{\text {o Ciclo }}$ & 41,3 & 23,7 & 15,1 & 7,3 & 7,9 & 4,8 \\
\hline $3^{\text {o Ciclo }}$ & 36,2 & 27,7 & 21,4 & 7,2 & 4,8 & 2,6 \\
\hline E.S.O & 33,4 & 30,0 & 16,7 & 8,2 & 8,2 & 3,0 \\
\hline
\end{tabular}

Por otra parte, las habilidades de comunicación positiva, como, por ejemplo, la escucha activa, facilitan la cohesión grupal. Así, el niño/a necesita ser escuchado y poder expresar sentimientos, preferencias y temores, a la vez que sentirse importante cuando se le tiene en cuenta. En definitiva, esto le ayudaría a crecer y desarrollarse como persona. La comunicación en el seno de cualquier grupo se lleva a cabo mediante el diálogo cercano y continuado como forma de acción recíproca, que incluye, entre otros, un aspecto fundamental: la escucha. Estar siempre dispuesto a escuchar a los demás, mostrar atención, es uno de los aspectos básicos que propician el diálogo, medio idóneo para que se establezca una buena comunicación.

La comunicación dentro de un grupo supone una interacción donde se posibilita el intercambio de puntos de vista, necesidades, etc. El resultado de esta comunicación será siempre beneficioso para el entorno relacional del grupo por el simple hecho de intercambiar vivencias y abrir causas para la mutua adaptación. Intentamos conocer desde esta perspectiva cómo piensan los escolares, respecto a la actitud de escucha (tabla $n^{\circ} 6$ ).

Los datos muestran que el mayor porcentaje se sitúa en torno a "muy de acuerdo" (55'3\%); sumado al 31'5\% "de acuerdo", nos arroja un resultado del 86' $8 \%$, lo cual deja claro que los escolares, al menos en teoría, piensan que la actitud de escuchar al otro es necesaria y positiva.

TABLA N ${ }^{\circ}$ 6. Grado de acuerdo respecto a si "Es bueno escuchar a los demás".

\begin{tabular}{|c|c|c|c|c|c|}
\hline $\begin{array}{c}\text { Muy de } \\
\text { cuerdo }\end{array}$ & De acuerdo & Indiferente & $\begin{array}{c}\text { En } \\
\text { desacuerdo }\end{array}$ & $\begin{array}{c}\text { Muy en } \\
\text { desacuerdo }\end{array}$ & NS/NC \\
\hline 55,3 & 31,5 & 6,6 & 1,6 & 1,3 & 3,7 \\
\hline
\end{tabular}

\subsubsection{Intercambios sociales: prestaciones y costos}

Los intercambios sociales entre iguales proporcionan a los niños una serie de beneficios y bienes, de prestaciones y costes, que se ponen en marcha en el mismo proceso de interacción, pero cuyas consecuencias van más allá de la mera acción 
PETRA M. a PÉREZ ALONSO-GETA, PAZ CÁNOVAS LEONHARDT Y ENRIQUE GERVILLA CASTILLO

VALORES, ACTITUDES Y COMPETENCIAS BÁSICAS DEL ALUMNO EN LA ENSEÑANZA OBLIGATORIA

puntual, condicionando y sacando o no provecho para el futuro de las experiencias de aprendizaje que las mismas interacciones proporcionan.

En las teorías psicológicas del intercambio, y sin entrar aquí en especificaciones, es frecuente hablar de recompensas, costos y beneficios como resultados obtenidos en la interacción social, entendiendo que los individuos tratan de obtener el máximo beneficio de la misma. Al tratar aquí la interacción entre iguales "en niños", nos vamos a centrar, más que en los intercambios de tipo económico, en recursos más sutiles como el afecto, la consideración (estatus), la información, etc., con planteamientos cercanos a la Teoría de los recursos de Foa y Foa. Estos recursos pueden ser productos tangibles y materiales, como los apuntes y libros u objetos, y más abstractos, como el afecto y la estima, el tiempo que se ofrecen y entregan sin perder nada en ello (tabla $n^{\circ} 7$ ).

\section{TABLA $\mathrm{N}^{\circ} 7$. Frecuencia de intercambios sociales en relación a la prestación de distintos recursos materiales y no materiales.}

\begin{tabular}{|l|c|c|c|c|c|c|}
\hline & Siempre & $\begin{array}{c}\text { Muchas } \\
\text { veces }\end{array}$ & $\begin{array}{c}\text { Algunas } \\
\text { veces }\end{array}$ & $\begin{array}{c}\text { Muy } \\
\text { pocas veces }\end{array}$ & Nunca & NS/NC \\
\hline $\begin{array}{l}\text { Ayudar a algún amigo en los estudios, } \\
\text { aunque pierda mi tiempo }\end{array}$ & 17,5 & 17,6 & 37,1 & 16,8 & 8,5 & 2,6 \\
\hline $\begin{array}{l}\text { Dejar los apuntes, libretas, etc. } \\
\text { para que algún compañero } \\
\text { o amigo vaya mejor en los estudios }\end{array}$ & 26,9 & 25,3 & 23,9 & 9,3 & 10,2 & 4,5 \\
\hline $\begin{array}{l}\text { Dejar o prestar mis cosas } \\
\text { (cuentos, juguetes, etc.) }\end{array}$ & 35,6 & 35,3 & 19,4 & 4,2 & 1,6 & 3,9 \\
\hline
\end{tabular}

En primer lugar, podemos observar cómo los niños parecen estar más dispuestos a la prestación de bienes y recursos materiales ("dejar apuntes", 26'9\%, $25^{\prime} 3 \%$; "dejar, prestar mis cosas", 35'6\%, 35'3\%) que a la prestación de un bien, hoy en día tan preciado, como es el propio tiempo ("ayudar a algún amigo en los estudios aunque pierda mi tiempo" 17'5\%, 17,6\%). Esta posibilidad parece no gustar tanto a los niños y confirma la tendencia que apunta hoy al establecimiento de una sociedad más individualista.

Si agrupamos las dos primeras variables ("Siempre" y "muchas veces") se establece el siguiente ranking: "dejar o prestar mis cosas (cuentos, juguetes, etc.)", 70'9\%; "dejar los apuntes, libretas, etc., para que algún compañero o amigo vaya mejor en los estudios", 52'2\% y finalmente, a mucha distancia, "ayudar a algún amigo en los estudios, aunque pierda mi tiempo", con 35'1\%. Se observa que se muestran más dispuestos a dejar sus cuentos, juguetes, etc., que aquello que se relaciona con los estudios. Tal vez se esté poniendo de manifiesto, con estos datos, un clima de mayor competitividad en el contexto escolar.

Si bien es cierto que en los niños más pequeños los valores de solidaridad y generosidad, el compartir, se pueden encontrar poco desarrollados, ya que todavía tienen que aprender la importancia y necesidad del grupo y advertir con suficiente 
PETRA M. ․ PÉREZ ALONSO-GETA, PAZ CÁNOVAS LEONHARDT Y ENRIQUE GERVILLA CASTILLO VALORES, ACTITUDES Y COMPETENCIAS BÁSICAS DEL ALUMNO EN LA ENSEÑANZA OBLIGATORIA

nitidez el valor que tiene compartir las cosas. A edades tempranas, el niño tiene una tendencia al egocentrismo muy acusada, percibe las cosas en tanto son beneficiosas para el yo individual. Sin embargo, los escolares, progresivamente, deberán y podrán ir interiorizando esos valores solidarios, si los padres y profesores les proporcionan situaciones diversas donde puedan apreciar el significado que tiene "Compartir" en sus distintas posibilidades y repercusiones. En definitiva, es importante que el niño aprenda a compartir, a "prestar sus cosas, aunque sean valiosas", a ser solidario "ayudando a los demás". Sólo ello le permitirá en el futuro traducir y transferir a acciones concretas los valores sociales que le llevarán a sentirse a gusto y autorrealizado en el grupo (familia, escuela y amigos).

En línea con lo anterior, presentamos a continuación un dato que nos resulta preocupante (tabla $n^{\circ} 8$ ). Parece ser que, a medida que aumenta el nivel educativo, disminuye sensiblemente la frecuencia de prestación del propio tiempo como forma de apoyo a los iguales. Desde nuestra perspectiva, este dato tiene una clara explicación. Los escolares son fruto de su ambiente y de su época, y hoy prima la eficacia, el individualismo, la búsqueda de la posesión material como forma de relevancia social. Nuestro entorno se encuentra cada vez más impregnado de una cultura individualista y, en algunas vertientes, deshumanizada. Y ello se manifiesta también en los niños.

TABLA $\mathrm{N}^{\circ}$ 8. Frecuencia en relación a "ayudar a algún amigo en los estudios, aunque pierda mi tiempo» según nivel educativo (porcentajes).

\begin{tabular}{|c|c|c|c|c|c|c|}
\hline & Siempre & $\begin{array}{c}\text { Muchas } \\
\text { veces }\end{array}$ & $\begin{array}{c}\text { Algunas } \\
\text { veces }\end{array}$ & $\begin{array}{c}\text { Muy pocas } \\
\text { veces }\end{array}$ & Nunca & NS/NC \\
\hline $2^{\circ}$ Ciclo & 21,8 & 20,1 & 34,2 & 11,0 & 8,5 & 4,4 \\
\hline $3^{\circ}$ Ciclo & 20,1 & 16,7 & 36,6 & 17,1 & 7,1 & 2,4 \\
\hline E.S.O. & 11,6 & 16,4 & 39,8 & 21,2 & 9,8 & 1,2 \\
\hline
\end{tabular}

\section{Aceptación del grupo}

Conseguir la aceptación de sus coetáneos constituye una necesidad grande en niños y adolescentes, y la socialización de los niños y niñas se ve incrementada poderosamente por las interacciones con los iguales en estos grupos o pandillas. Grupos que los mismos niños crean, aunque no posean una estructura estable y formalizada. El sentirse miembro de un grupo significa su aceptación en el mismo, a veces también un estatus de privilegio frente a un grupo más grande. Esto proporciona al niño seguridad y la sensación de tener un lugar en el mundo social (tabla $n^{\circ}$ 9).

Los datos muestran que, en un 62'6\% (29'7\% "muy de acuerdo" y 32'9\% "de acuerdo"), los niños consideran importante pertenecer a una pandilla o grupo. Sólo el 5'9\% se muestra "muy en desacuerdo". La aceptación de una pandilla en estas edades trae consigo grandes recompensas, como venimos señalando, y ellos lo valoran en esta medida. Sin embargo, la pertenencia a uno de estos grupos no siempre está 
PETRA M. a PÉREZ ALONSO-GETA, PAZ CÁNOVAS LEONHARDT Y ENRIQUE GERVILLA CASTILLO

VALORES, ACTITUDES Y COMPETENCIAS BÁSICAS DEL ALUMNO EN LA ENSEÑANZA OBLIGATORIA

TABLA $\mathrm{N}^{\circ}$ 9. Grado de acuerdo a "es importante pertenecer a una pandilla o grupo de amigos".

\begin{tabular}{|c|c|c|c|c|c|}
\hline Muy de acuerdo & De acuerdo & Indiferente & En desacuerdo & $\begin{array}{c}\text { Muy en } \\
\text { desacuerdo }\end{array}$ & NS/NC \\
\hline 29,7 & 32,9 & 20,5 & 8,1 & 5,9 & 2,9 \\
\hline
\end{tabular}

en manos de los propios niños. Los adultos y las condiciones de vida actuales, según ya hemos indicado, pueden restringir las oportunidades reales y, aún dentro de las oportunidades existentes, los padres pueden determinar las características de los grupos en los que se permite entrar a los hijos e hijas. Por otra parte, dentro de un grupo, los niños y las niñas buscan su lugar. Se comparan continuamente con los demás y se valoran a sí mismos de acuerdo con diversos rasgos (popularidad, fuerza, atractivo, agresividad, etc.). Estas valoraciones de los demás tienen importancia capital para la idea que de "sí mismo" se hace el niño (tabla $n^{\circ} 10$ ).

A medida que aumenta el nivel educativo, adquiere mayor importancia para los niños/as el pertenecer a una pandilla o grupo de amigos. Este es un dato lógico, ya que el alumno de ESO, en algunos casos pre o ya adolescente, siente la necesidad de integrarse en grupos o pandillas. La implicación en un grupo es algo totalmente recomendable en todas las etapas evolutivas y más en la adolescencia. Ciertamente, además de posibilitar un conocimiento del mundo, necesario de cara a la configuración de su personalidad, ofrece la posibilidad de conocerse a sí mismo y conocer a los demás.

TABLA N ${ }^{\circ} 10$. Grado de acuerdo respecto a "es importante pertenecer a una pandilla o grupo de amigos" según nivel educativo.

\begin{tabular}{|l|c|c|c|c|c|c|}
\hline & $\begin{array}{c}\text { Muy de } \\
\text { acuerdo }\end{array}$ & De acuerdo & Indiferente & $\begin{array}{c}\text { En } \\
\text { desacuerdo }\end{array}$ & $\begin{array}{c}\text { Muy en } \\
\text { desacuerdo }\end{array}$ & NS/NC \\
\hline $2^{\text {o Ciclo }}$ & 26,6 & 28,8 & 23,0 & 10,0 & 7,5 & 4,1 \\
$3^{\circ}$ Ciclo & 28,6 & 30,7 & 22,1 & 8,2 & 6,7 & 3,7 \\
E.S.O. & 33,3 & 38,4 & 16,9 & 6,4 & 3,8 & 1,2 \\
\hline
\end{tabular}

\subsubsection{Importancia de la amistad en la educación obligatoria}

Entendemos que el desarrollo de la conducta social durante la infancia es una preparación importante para las relaciones de amistad. Así, la actitud de preocupación por el otro, la ayuda mutua, la comprensión, el respeto se pueden ir adquiriendo día a día, en las múltiples experiencias vividas en la escuela. En los apartados anteriores, al hablar de la interacción con iguales nos referíamos a las relaciones de camaradería propias de la etapa primaria. Cabe la posibilidad de que estas relaciones desemboquen más tarde en otro tipo de relación más profunda denominada de amistad. Consideramos que este es un aspecto lo suficientemente 
relevante, para la competencia social, como para incidir en él educativamente desde los primeros años de la escolarización.

ARISTÓTELES ${ }^{2}$, señalaba que «el hombre es un animal social formado naturalmente para la convivencia. El hombre necesita amigos". Sin embargo, en nuestra sociedad actual existe la tendencia contraria. Se fomentan las relaciones impersonales en detrimento de las relaciones de amistad. Estamos ante un tipo de sociedad impersonal, excesivamente tecnificada, competitiva y deshumanizada, en la que sin embargo es necesario educar para la amistad como forma de mejora del hombre y de la propia sociedad. La educación para la amistad supone en la educación obligatoria intentar que los alumnos desarrollen aspectos, para nosotros mucho más significativos que los contenidos puramente informativos, como son valores, competencias, normas y sentimientos socialmente positivos. Desde la educación debemos ayudar al niño/a a que se aleje de posturas egocéntricas, contrarias al desarrollo de la amistad, a saber, egoísmo, excesivo individualismo, competividad. Se trataría de un aprendizaje para la convivencia.

En esta línea, intentamos conocer algunos datos de los niños/as de 8 a 14 años en relación a distintos aspectos referentes a la amistad (tabla $\left.n^{\circ} 11\right)$.

TABLA $N^{\circ} 11$. Grado de acuerdo con distintas proposiciones referentes a la amistad (Porcentajes).

\begin{tabular}{|l|c|c|c|c|c|c|}
\hline & $\begin{array}{c}\text { Muy de } \\
\text { acuerdo }\end{array}$ & $\begin{array}{c}\text { De } \\
\text { acuerdo }\end{array}$ & Indiferente & $\begin{array}{c}\text { En } \\
\text { desacuerdo }\end{array}$ & $\begin{array}{c}\text { Muy en } \\
\text { desacuerdo }\end{array}$ & NS/NC \\
\hline $\begin{array}{l}\text { La amistad y la convivencia hacen más } \\
\text { agradable la vida }\end{array}$ & 58,4 & 27,4 & 6,1 & 2,3 & 1,5 & 4,5 \\
\hline $\begin{array}{l}\text { Lo mejor de la amistad es la ayuda } \\
\text { mutua entre todos }\end{array}$ & 55,5 & 29,8 & 6,4 & 2,3 & 1,1 & 4,9 \\
\hline $\begin{array}{l}\text { La ayuda desinteresada a los amigos } \\
\text { unida al esfuerzo de cada uno permite } \\
\text { hacer grandes cosas }\end{array}$ & 35,8 & 29,3 & 19,8 & 4,8 & 4,8 & 5,7 \\
\hline
\end{tabular}

En conjunto, y en relación con el primer ítem, el 85'8\% globalmente muestra su "acuerdo". Parece que los niños tienen claro los beneficios que representa la amistad y convivencia para su vida. Por otro lado, el $85^{\prime} 3 \%$ manifiesta su acuerdo respecto a uno de los aspectos más significativos de la amistad: la ayuda mutua. De hecho, la verdadera amistad excluye actitudes egoístas. Hay que insistir, por tanto, en que la amistad busca el beneficio mutuo entre los amigos. Por último, observamos que el grado de acuerdo baja significativamente $\left(65^{\prime} 1 \%\right)$ cuando preguntamos a los niños/as acerca del sentido que tiene la ayuda desinteresada y el esfuerzo personal en la amistad. Aumentando, lógicamente, los "indiferentes" ante esta proposición. Es cierto que la amistad se fomenta con la ayuda desinteresada, pero también se basa en la realidad individual de cada amigo/a que hace posible la relación de amistad.

2. ARISTÓTELES, Ética a Nicomaco, Libro VIII. Centro de Estudios Constitucionales, Madrid. 
PETRA M. ${ }^{a}$ PÉREZ ALONSO-GETA, PAZ CÁNOVAS LEONHARDT Y ENRIQUE GERVILLA CASTILLO

VALORES, ACTITUDES Y COMPETENCIAS BÁSICAS DEL ALUMNO EN LA ENSEÑANZA OBLIGATORIA

\subsubsection{Pautas educativas para el desarrollo de la competencia social en la enseñanza obligatoria: las habilidades sociales y la conducta prosocial}

Sin duda, la escuela interviene de forma decisiva en el desarrollo social del alumno/a de la enseñanza obligatoria. Puede ser considerada, en opinión de MINUCHIN y SHAPIRO (1983), como un microcosmos de la sociedad más amplia en el cual los niños desarrollan básicas comprensiones de sí mismos, del mundo social y del lugar que ocupan en el grupo. La escuela es un escenario especialmente significativo para el estudio de los procesos de socialización, debido a que los niños encuentran en ésta a dos agentes de socialización: los adultos y sus iguales. El desarrollo personal de los valores sociales, el aprendizaje de babilidades sociales y de la conducta prosocial se logra a partir de las específicas condiciones de interacción que la escuela ofrece, es decir, las interacciones con los adultos y grupos de iguales. Así, el niño/a necesita de la escuela, y ésta debe proporcionarle oportunidades para mantener dichas interacciones sociales en condiciones de igualdad y respeto mutuo.

Mediante el proceso de socialización, el niño debe ir aprendiendo ciertas conductas y destrezas sociales (habilidades sociales), que le van a posibilitar interactuar con los demás de forma satisfactoria. Progresivamente, va aprendiendo a comportarse socialmente de un modo apropiado. La escuela y todo lo que ella comporta ejerce un papel fundamental en la adquisición de estas conductas. Constituye un espacio educativo único para el aprendizaje y entrenamiento de las habilidades sociales, porque proporciona gran variedad de situaciones adecuadas, y el profesor, como adulto y modelo significativo para el niño en su etapa escolar, influye de forma clara en la enseñanza de las mismas. En definitiva, la escuela debe incluir programas de habilidades sociales en sus curricula con el fin de promover en los alumnos una adecuada competencia social. De igual modo, el grupo de iguales, como decíamos, cumple un papel destacado en el desarrollo de la competencia social de la infancia.

Si bien las habilidades sociales hacen más eficaces nuestras relaciones interpersonales, la conducta prosocial o altruista supone acciones que tienden a beneficiar a otras personas sin que exista la previsión de recompensa exterior. Incluye conductas socialmente deseables tales como ayudar, compartir, cooperar. La conducta prosocial se encuentra determinada por ciertos factores que podemos agrupar en factores personales (edad, desarrollo cognitivo, afectivo y social), el contexto familiar y escolar (parece lógico que cuando desde la familia y la escuela se impulsa la sensibilidad social, las necesidades del otro, la conducta prosocial se incrementa) y, por último, la cultura (los valores socioculturales inciden en que sus miembros sean proclives o no a las conductas prosociales). En suma, enseñar a los niños/as a ayudar a compartir y cooperar debe ser una de las metas de la enseñanza obligatoria en su intento de estimular el desarrollo integral de éstos. 
76 PETRA M. ${ }^{a}$ PÉREZ ALONSO-GETA, PAZ CÁNOVAS LEONHARDT Y ENRIQUE GERVILLA CASTILLO VALORES, ACTITUDES Y COMPETENCIAS BÁSICAS DEL ALUMNO EN LA ENSEÑANZA OBLIGATORIA

\subsection{La salud como competencia básica en la educación obligatoria}

Con la actual reforma educativa, la promoción de la salud en la escuela adquiere una nueva dimensión más sólida y esperanzadora al ser tratada como eje transversal. La salud se convierte en una competencia básica y en compromiso vital por parte del alumnado y profesorado desde la etapa infantil hasta la educación secundaria obligatoria. Es necesario, pues, que el centro educativo, en su conjunto, sea un "medio saludable", desde el que se posibilite el desarrollo de los alumnos, en todos y cada uno de los aspectos y manifestaciones de su personalidad.

Presentamos a continuación, algunos datos acerca de cómo valoran los escolares de 8 a 14 años la salud, si es algo que les inquieta y preocupa, si son conscientes de que existe, por ejemplo, relación entre salud y alimentación. En definitiva, cómo se posicionan ante determinados aspectos fundamentales con respecto a la salud (tabla $n^{\circ} 12$ ).

TABLA $\mathrm{N}^{\circ} 12$. Grado de acuerdo de los escolares con distintas proposiciones referidas al concepto de SALUD.

\begin{tabular}{|l|c|c|c|c|c|}
\hline & $\begin{array}{c}\text { Muy de } \\
\text { acuerdo }\end{array}$ & $\begin{array}{c}\text { De } \\
\text { acuerdo }\end{array}$ & Indiferente & $\begin{array}{c}\text { En } \\
\text { desacuerdo }\end{array}$ & $\begin{array}{c}\text { Muy en } \\
\text { desacuerdo }\end{array}$ \\
\hline $\begin{array}{l}\text { Tener salud es lo más importante } \\
\text { en la vida }\end{array}$ & 72,6 & 19,9 & 4,9 & 2,2 & 0,4 \\
\hline Prefiero tener salud a tener dinero & 75,9 & 15,2 & 5,4 & 1,6 & 1,9 \\
\hline $\begin{array}{l}\text { La salud depende de una buena, } \\
\text { correcta y equilibrada alimentación. }\end{array}$ & 57,9 & 28,3 & 8,2 & 3,4 & 2,2 \\
\hline
\end{tabular}

En conjunto, los escolares españoles están muy de acuerdo con el hecho de preferir tener salud a tener dinero (75'9\%) así como también coinciden en el mismo grado de acuerdo respecto a la proposición "tener salud, es lo más importante en la vida" (72'6\%), frente a los que conceden escasa consideración, o están muy en desacuerdo, (0'4\% y 1'9\% respectivamente).

Dentro de la misma línea, cuando se trata de asegurar que "la salud depende de una buena, correcta y equilibrada alimentación", los porcentajes disminuyen sensiblemente con respecto a los ítems anteriores. El 57'9\% se muestra totalmente de acuerdo y sólo el 2'2\% se manifiesta muy en desacuerdo.

En este sentido, se observa que en cuanto a sus creencias los niños apuestan por una vida saludable y mantienen una idea correcta de los hábitos dietéticos a seguir para conseguir el óptimo estado salud, es decir, son conscientes de la estrecha relación existente entre "salud, alimentación y desarrollo".

El resultado es alentador, la mayoría ven natural el hecho de apreciar a lo sumo una vida saludable, considerando indispensable la elección de un estilo de vida y el mantenimiento de unas condiciones de vida saludables y la adquisición de hábitos correctos de alimentación. 


\section{TRANSMISIÓN, APRENDIZAJE DE VALORES Y COMPETENCIAS ESCOLARES, 8-14 AÑOS}

La educación, como primer vehículo de transmisión cultural, a través de la enseñanza obligatoria que aquí nos ocupa, tiene el papel de viator de la propia competencia personal. Sin embargo, para que ello sea posible, tanto la normativa legal como la acción pedagógica han de promover el aprendizaje de competencias y valores por parte del alumno. El proceso de enseñanza-aprendizaje conlleva la interacción efectiva y afectiva entre profesores y alumnos; y ha de gozar de significado y relevancia para los alumnos, más aún cuando los mensajes que transmiten la escuela (junto con la familia, el estado o la iglesia) pueden carecer de credibilidad para algunos grupos de escolares en la época actual, en la sociedad occidental.

Para tratar de conocer en qué medida la transmisión de competencias y valores es "aprehendida" por los escolares españoles (8-14 años) ${ }^{3}$, hemos definido el prototipo del alumno "escolarmente integrado" $\mathrm{y}$, a partir de esa definición, llevado a cabo un análisis cluster, con el fin de establecer tipologías que definan el grado de adquisición de los valores y competencias por parte de los escolares en nuestro país.

Hemos partido del concepto base de "escolar integrado", para el cual la credibilidad e identificación con la institución educativa tiene sentido. Entendiendo que se establecen así las mejores condiciones para su socialización y educación en los valores y competencias propuestos. Los rasgos que hemos estimado definirían a este escolar integrado quedarían establecidos en torno a: considerarse buen estudiante, obediente, buena aceptación de la norma escolar, que tenga sentimientos de insatisfacción (se conmueva) ante la transgresión de la norma y finalmente que no vaya a la suya sin pensar en los demás.

Cruzados los correspondientes tipos de niños con los valores y competencias analizados (solidaridad, justicia, etc.), podremos conocer en qué medida se asocian éstos a los distintos tipos de alumnos. Realizados los correspondientes análisis tipológicos de la población escolar, se han obtenido dos tipologías básicas (tabla n 13).

TABLA N ${ }^{\circ}$ 13. Nominación del cluster $n^{\circ}$ 1. Descripción de los items $n^{\circ}$ de casos. Media general de contribución de los items a los distintos clusters $y$ media de contribución al cluster.

\begin{tabular}{|l|c|c|c|}
\hline \multicolumn{1}{|c|}{ Alumnos escolarmente integrados } & \multicolumn{3}{c|}{$\mathrm{n}^{\circ}$ de casos: 1.072} \\
\hline \multicolumn{1}{|c|}{ Descripción } & X Gral. & X Cluster & Xc-Xg \\
\hline Cuando has hecho algo mal te sientes mal, aunque no te pillen & 4.136 & 4.537 & +0.401 \\
\hline $\begin{array}{l}\text { Ser obedientes (hacer lo que te dicen mis profesores) porque así están } \\
\text { contentos conmigo. }\end{array}$ & 3.943 & 4.291 & +0.348 \\
\hline ¿Cómo te van los estudios? & 3.912 & 4.285 & +0.373 \\
\hline ¿Qué importancia tiene para tí estudiar para aprobar? & 4.416 & 4.732 & +0.216 \\
\hline Es mejor que te digan lo que puedes hacer o no, para no equivocarte & 4.050 & 4.358 & +0.308 \\
\hline ¿Qué importancia tiene para ti "Ir a la mía, sin pensar en los demás"? & 2.643 & 2.605 & -0.38 \\
\hline
\end{tabular}

3. Los datos corresponden a la investigación para determinar los valores, estilos de vida y hábitos lectores de los escolares españoles en el seguimiento de 8 a 14 años realizada en el INCIE (Universidad de Valencia) en 1997. Financiada por S.M. 
Se trata de escolares que "siempre" se sienten mal cuando transgreden la normas aunque no los pillen. Generalmente, van "muy bien" o "bien" en los estudios. Son obedientes y piensan que es mejor disponer de un contexto normativo claro, para no equivocarse. Tiene para ellos "mucha importancia" estudiar para aprobar y en términos generales, no es "importante" para ellos ir a la suya, sin pensar en los demás.

En cuanto a los valores y competencias básicas que se asocian con los distintos valores, con datos estadísticamente significativos, aparecen los siguientes ítems (tabla $n^{\circ} 14$ ).

TABLA $\mathrm{N}^{\circ} 14$. Valores $y$ competencias. Cluster $n^{\circ} 1$.

\begin{tabular}{|l|c|}
\hline \multicolumn{1}{|c|}{ Descripción } & \multicolumn{1}{c|}{ Variables } \\
\hline Me gusta sentirme orgulloso de mi grupo y su forma de hacer las cosas, todos a una & (5) Muy de acuerdo \\
\hline Portarse bien hace que las personas estén contentas consigo mismo & (5) Muy de acuerdo \\
\hline Es bueno escuchar a los demás & (5) Muy de acuerdo \\
\hline Hay que hablar antes que pelear para solucionar los problemas & (5) Siempre \\
\hline Cuando voy de excursión suelo traer los desperdicios a casa o tirar a la papelera & (5) Siempre \\
\hline $\begin{array}{l}\text { Suelo ser obediente y mantener buenas relaciones con los demás para que me } \\
\text { consideren legal, bueno }\end{array}$ & (5) Siempre \\
\hline Suelo defender a alguien cuando se le trata injustamente & (5) Siempre \\
\hline $\begin{array}{l}\text { Para enriquecerse como persona hay que ser amigo de personas diferentes } \\
\text { (raza, cultura) }\end{array}$ & (5) Muy de acuerdo \\
\hline $\begin{array}{l}\text { Todos solidariamente debemos buscar una sociedad sin injusticia aunque nos cueste } \\
\text { esfuerzo y sacrificios }\end{array}$ & (5) Muy de acuerdo \\
\hline Hay que ayudar a conseguir las causas justas & (5) Muy de acuerdo \\
\hline
\end{tabular}

Llama la atención la coherencia que manifiestan estos escolares, ya que, mayoritariamente, puntúan con la máxima significación, tanto para los valores ("muy de acuerdo") como para la actuación conforme a los mimos ("siempre").

Cruzados con las variables poblacionales y con significación estadísticas aparecen los siguientes resultados:

Edad: 8-11 años mayoritariamente.

Sexo: tanto niños como niñas, aunque éstas en mayor proporción.

Escolarización: $2^{\circ}$ y $3^{\circ}$ ciclo.

Tipo de colegio: tanto público como privado y concertado.

Hábitats de mayor incidencia: Valencia, Vizcaya, Galicia y Las Palmas.

Como puede observarse la variable edad, los más pequeños, y en parte el sexo (niñas) configuran un grupo de escolares caracterizados por la integración escolar, la competencia emocional y social (tabla $\mathrm{n}^{\circ} 15$ ).

Se trata de escolares que, contrariamente a los anteriores, no se sienten mal cuando han hecho algo mal. Los estudios les van "regular" "Suficiente" o "mal". No suelen ser obedientes y no tiene para ellos "importancia" estudiar para aprobar. No 
TABLA N ${ }^{\circ}$ 15. Nominación del cluster $n^{\circ}$ 2. Descripción de los items, $n^{\circ}$ de casos. Media general de contribución de los ítems a los distintos clusters y media de contribución al cluster.

\begin{tabular}{|l|c|c|c|}
\hline Alumnos escolarmente no integrados & \multicolumn{3}{|c|}{$\mathrm{n}^{\circ}$ de casos 528} \\
\hline Descripción & $\mathrm{Xg}$ & $\mathrm{Xc}$ & $\mathrm{Xc}-\mathrm{Xg}$ \\
\hline Cuando has hecho algo mal te sientes mal aunque no te pillen & 4.136 & 3.324 & -0.812 \\
\hline $\begin{array}{l}\text { Ser obediente (hacer lo que dicen mis profesores) porque así están } \\
\text { contentos conmigo }\end{array}$ & 3.943 & 3.239 & -0.704 \\
\hline ¿Cómo te van los estudios? & 3.912 & 3.155 & -0.757 \\
\hline ¿Qué importancia tiene para ti estudiar para "aprobar"? & 4.416 & 3.777 & -0.639 \\
\hline Es mejor que te digan lo que puedes hacer, o no, para no equivocarte & 4.050 & 3.426 & -0.624 \\
\hline ¿Qué importancia tiene para ti "ir a la mía sin pensar en los demás"? & 2.643 & 2.720 & +0.077 \\
\hline
\end{tabular}

les gusta que les digan lo que han de hacer. También, frente a los anteriores suelen "ir a la suya" sin pensar en los demás. Son alumnos que, en términos generales conceden escaso valor a la escuela y a cuanto ella representa (normas, estudios, obediencia al profesorado, etc.).

En cuanto a los valores y competencias básicas con los que se asocia este grupo de niños, con datos estadísticamente significativos, los resultados son los que siguen (tabla $\left.\mathrm{n}^{\circ} 16\right)$.

TABLA $\mathrm{N}^{\circ} 16$. Valores y competencias. Cluster $n^{\circ} 2$.

\begin{tabular}{|l|c|}
\hline \multicolumn{1}{|c|}{ Descripción } & Variables \\
\hline $\begin{array}{l}\text { Me gusta sentirme orgulloso del grupo y su forma de hacer las cosas } \\
\text { todos a una }\end{array}$ & (2) En desacuerdo \\
\hline Portarse bien hace que las personas estén contentos consigo mismo & (2) En desacuerdo \\
\hline Es bueno escuchar a los demás & (2) En desacuerdo \\
\hline Sueles ayudar a algún amigo en los estudios aunque pierdas tu tiempo & (2) (1) Muy pocas veces, nunca \\
\hline Hablar antes que pelear para solucionar los problemas & (2) Muy pocas veces \\
\hline Pegar cuando se lo merecen & (4) (3) Muchas veces, algunas veces \\
\hline $\begin{array}{l}\text { Cuando vas de excursión suelo tirar a la papelera o traer } \\
\text { los desperdicios a casa }\end{array}$ & (3) (2) Algunas veces, muy pocas veces \\
\hline Utilizar la fuerza cuando hace falta & (3) Algunas veces \\
\hline $\begin{array}{l}\text { Ser obediente y mantener buenas relaciones con los demás, } \\
\text { para que te consideren legal, bueno }\end{array}$ & (3) (2) Algunas veces, muy pocas veces \\
\hline Defender a alguien cuando se le trata injustamente & (3) (2) Algunas veces, muy pocas veces \\
\hline Quien pega primero pega mejor & (2) (3) Desacuerdo, indiferente \\
\hline $\begin{array}{l}\text { La tolerancia hacia los demás que son diferentes a nosotros } \\
\text { (pensar, vestir) cuesta pero nos hace más felices }\end{array}$ & (4) (3) De acuerdo, indiferente \\
\hline $\begin{array}{l}\text { Hay que estar dispuesto a trabajar por los demás } \\
\text { Todos solidariamente debemos buscar una sociedad sin injusticias }\end{array}$ & (4) (3) De acuerdo, indiferente, \\
\hline Hay que ayudar a conseguir las causas justas & (4) (3) De acuerdo, indiferente \\
\hline
\end{tabular}


Cruzados con las variables poblaciones tenemos el siguiente perfil poblacional.

Edad: 12 a 14 años en mayor proporción.

Sexo: niños y niñas si bien, con mayor números de niños.

Escolarización: E.S.O y $8^{\circ}$.

Colegio: público y privado con una mayor incidencia del público.

Hábitat: Barcelona, Madrid, Sevilla, pero sobre todo en Sevilla.

Como puede apreciarse la variable edad y la escolarización en E.S.O. están configurando en gran medida este grupo de escolares, incompetentes social y afectivamente y poco integrados a nivel individual y social.

Parece que los puntos de referencia tradicionales no tienen o tienen escasa significación para ellos. Aparecen desubicados en relación a los aspectos más clásicos de la transmisión de valores en el ámbito escolar. Cuanto decimos es tanto más grave por cuanto a medida que avanza la escolarización, la integración y el compromiso personal con los valores prosociales y la competencia social y emocional disminuyen.

\section{CONCLUSIÓN Y DiSCUSIÓN}

Nuestros escolares, en términos generales, están siendo socializados en un medio que ofrece unas perspectivas de seguridad sin precedentes, en lo que respecta a la satisfacción de las necesidades básicas. Están creciendo dentro de los valores y estilos de vida propios del postmaterialismo que en nuestro país, como en el resto de las sociedades occidentales, frente a la búsqueda de la seguridad material y física pone el énfasis en la calidad de vida, Necesidades intelectuales y de autorealización (de pertenencia, estima, ocio, estéticas, etc.), mayor preocupación por la salud y el medio ambiente, por los aspectos sociales, por los derechos y libertades personales, y por el aumento del nivel de educación. A la vez que el abandono de las grandes finalidades y de la finalidad "de logro" de las necesidades básicas.

La LOGSE, fruto de su tiempo, incide y anima también a la adopción de estos valores postmaterialistas, dando mayor importancia a los mismos en el curriculum escolar. Estos valores, en general, se han visto reflejados en el ranking de preferencias que los escolares manifiestan. Los datos parecen acordes con el peso que tiene, en las creencias y conductas de los individuos, el aprendizaje socio-cognitivo, que la educación y el contexto social ponen en marcha. Muestran "conocimiento" y "apreciación" de los valores ecológicos, prosociales, etc., propuestos en la LOGSE. Si bien, cuando se trata de poner en práctica los mismos y ser competentes en esos valores, los porcentajes bajan considerablemente. Parece que conocen los valores en que se les está educando, pero muestran una actitud y acción menos favorable cuando se trata de llevar a cabo las conductas propuestas en lo inmediato y cotidiano.

Consecuentemente, la intervención sobre solidaridad y tolerancia ha de incidir en generar, prioritariamente, competencia con lo más cercano y conocido (compañero de al lado), y en el campo de "lo conductual", de la acción y del compromiso. 
Igual cabría decir de los valores y competencias de naturaleza ecológica, ya que, si bien tienen claro lo que supone el valor y cuidado de la naturaleza, a la hora de implicarse y traer los desperdicios a casa, las puntuaciones bajan considerablemente.

En relación a los valores intelectuales, habría que concluir que, si bien, en términos generales, los escolares se sitúan en una buena posición, ello es, en buena medida, gracias a las niñas y a los alumnos más pequeños. Si tenemos en cuenta -como se ha argumentado- la importancia capital del fomento de estos valores en la época actual, cabría señalar que los datos no son satisfactorios, por cuanto la inquietud intelectual, que la escuela está obligada a fomentar, no aumenta con el nivel de escolarización.

En cuanto a la competencia socio-emocional, si bien, los porcentajes han bajado considerablemente frente a los valores anteriores, la mayoría se manifiesta competente. Vuelve a observarse, no obstante, la misma tendencia apuntada, en relación a una menor valoración de las conductas más prosociales y emocionalmente competentes, por parte de los niños con mayor nivel de escolarización. Especial significación, en sentido negativo, presentan aquellos niños cuyo referente para generar su autoestima se aleja de los stándares escolares establecidos, como "portarse bien"; o aquéllos, relativamente numerosos, para los que la violencia constituye una forma de solución de conflictos. Asimismo, los que se muestran intolerantes e insolidarios con sus compañeros más cercanos (clase, juego, etc.).

En referencia a las habilidades sociales, hay que concluir que valoran muy positivamente "escuchar a los demás" y, en porcentajes también altos, "pertenecer a una pandilla o grupo de amigos", aunque con menos significación que la anterior. Asimismo, conceden un gran valor a la amistad, aunque tienen discretas posibilidades de relacionarse con sus amigos fuera del colegio. Los estilos de vida de la cultura urbana inciden negativamente en este hecho. La escuela, a falta de otras posibilidades, ha de proporcionar "espacios" y "tiempos" de juego libre a los niños, no sólo para posibilitar las relaciones de amistad, sino porque, a través del juego, aprenden de forma natural a ser competentes emocional y socialmente. Aprenden cómo superar la frustración, percibir la propia competencia (autoestima), a demorar la gratificación o adiestrarse en la ayuda mutua para conseguir la meta juntos. Como, también, el aprendizaje del respeto a la norma, que los niños se dan en el juego libre y cumplen porque no quieren quedarse fuera. Aprendizaje que más tarde ha de traducirse en el respeto de la norma democrática, la ley en la sociedad adulta. Ello es más necesario cuando los datos señalan que los escolares no suelen mayoritariamente "ayudar a los amigos en los estudios" y -solamente poco más de la mitad deja sus apuntes, libretas, etc., a sus compañeros o amigos.

En otro orden de cosas, si tratamos de explorar en qué forma el sistema educativo va conformando los valores y competencias de los escolares, hay que concluir que la mayoría se sitúan en torno al prototipo de "escolar integrado", que define una primera tipología, a la cual se asocian, específicamente, valores y competencias emocionales y prosociales (dialogantes, tolerantes, solidarios, etc.); sentimientos de grupo, igualdad y justicia. Es interesante poner de relieve la coherencia que presentan, mayoritariamente, estos niños entre pensamiento y acción. Aprecian, 
con la máxima significación, determinados valores y, en la misma medida, se comprometen y actúan. Son competentes.

Sin embargo, una segunda tipología, mayoritariamente integrada por los alumnos de la ESO, estaría definiendo a un alumno que, en la práctica, muestra escasas competencias. Con poco espíritu de grupo, no suele ayudar ni escuchar a los demás, afirma "pegar cuando se lo merecen". Suele, muy pocas veces, hablar antes que pelear para solucionar los problemas y no suele echar a la papelera o traerse los desperdicios a casa cuando van de excursión. Si bien a nivel mental suele mostrar un cierto "acuerdo" con proposiciones que hacen referencia a algunos valores prosociales, como la tolerancia o la solidaridad, aunque nunca con la máxima significación y siempre referido a situaciones lejanas. Muestran un menor grado de coherencia en el compromiso con los valores, a todos los niveles, que el grupo anterior. Estaríamos ante un tipo de escolar, en términos generales, desubicado en relación a los valores que la escuela promueve. Los datos son preocupantes, por cuando se trata, en mayor medida, de los alumnos que lleva más años de escolarización.

Por su parte, la evidencia empírica parece ser concluyente en la tesis de que los valores de la población adulta reflejan las experiencias vividas durante los años de formación en la misma medida, sino mayor, que las experiencias recientes. Ello, nos lleva a contemplar los datos aportados aún con mayor preocupación, por cuanto estaríamos, presumiblemente, ante futuros adultos, salvo experiencias contrarias, poco competentes socialmente y con escasos valores para orientarse.

El sistema educativo no puede olvidar la realidad de la sociedad actual, ni desentenderse de la problemática que estos alumnos plantean, para buscarles solución. La tarea no es fácil y no por ello deja de ser urgente. La necesidad y las bases para formar alumnos educados en los valores y competencias básicas ya han sido planteadas. Sólo apuntar que la solución debe ser un cometido de todos, administración educativa, profesores padres y alumnos.

\section{BIBLIOGRAFÍA}

ARISTÓTELES, Ética a Nicomaco, libro VIII. Centro de estudios constitucionales. Madrid.

BARNET, J. M. (1987) Empathy and related responses in children. En N. Eisenburg, J. Stranyers (eds). Empathy and its development. New York. Cambridge Press.

Estudio para determinar los valores estilos de vida y hábitos lectores en el seguimiento de 8 a 14 años (S.M.). INCIE. Valencia. 1997.

FRONDIZI, R. (1997) ¿Qué son los valores? F.C.E. México.

GECAS Y SCHWALBE, M. L. (983) "Beyond the lookin-glass self: Social structure and eficacybased self steem”. Soc. Psychology Quarterly 46-2, pág. 77-88.

GEERTZ, C. (1996). La interpretación de las culturas. Gedisa. Madrid.

GERVILLA, E. (1993) Los valores de la LOGSE. Revista Española de Pedagogía, n 195 , mayoagosto.

- (1997) Postmodernidad y Educación. Valores y cultura de los jóvenes, Dykinson, Madrid ( $3^{\mathrm{a}}$ edic.).

GOLEMAN, D. La salud emocional, Barcelona. Kairós.

MARTÍN, R. (1993) Los valores un desafio permanente. Cincel, Madrid. 
PETRA M. a PÉREZ ALONSO-GETA, PAZ CÁNOVAS LEONHARDT Y ENRIQUE GERVILLA CASTILLO

VALORES, ACTITUDES Y COMPETENCIAS BÁSICAS DEL ALUMNO EN LA ENSEÑANZA OBLIGATORIA

MINUCHIN, P. P., SHAPIRO, E. K. (1983) The school as context for social development. En Hetherington, E.M. (ed.) Hardbook of child psychology: Socialization, personality and social development. Vol. 4, New York. Wiley.

PÉREZ ALONSO-GETA, P. Mํㅡㄹ CÁNOVAS LEONHARDT, P. (1995) Niños y publicidad. INCIE. Universidad de Valencia: Estudio subvencionado FEJU.

- (1995) Los valores de los niños españoles, habilidades sociales y autoconcepto. Estudio subvencionado por FEJU. INCIE. Universidad de Valencia.

RESOLUCIÓN de 7 de septiembre de 1994, de la Secretaría de Estado de Educación, por la que se dan orientaciones para el desarrollo de la educación en valores en las actividades educativas de los centros docentes (BOE, núm. 228, 23, septiembre 1994).

ROCHE, R. (1995) Psicología y educación para la prosocialidad. Servicio publicaciones Universidad Autónoma de Barcelona. Barcelona.

ROKEACH (1973) The nature of buman values. Free Press. Nueva York.

VASTA, R. et. al. (1996) Psicología infantil, Ariel. Barcelona.

YEARLEY, L. (1997): "Tres visiones sobre la virtud». En GOLEMAN, D. La salud emocional, Barcelona. Kairós. 